\title{
Numerical Simulation of Enhanced Oil Recovery (EOR) studies for aqueous Gemini Surfactant-Polymer-Nanoparticle systems
}

\author{
Nilanjan $\mathrm{Pal}^{1}$ and Ajay Mandal ${ }^{2}$ \\ ${ }^{1}$ Indian School of Mines \\ ${ }^{2}$ Affiliation not available
}

May 11, 2020

\begin{abstract}
The article investigates the efficacy of gemini surfactant/polymer/nanoparticle flooding on chemical EOR. Initially, physicochemical behavior of aqueous chemical fluids were investigated via interfacial tension reduction, wettability alteration, adsorption, viscosity moderation and oil displacement experiments. During compositional analysis, Cartesian model with specified grid properties, injection flow-rate, well pattern, and rock-fluid characteristics was developed using CMG-STARS tool. Contour map analyses showed that oil saturation decreased from $~ 80 \%$ (initial) to $31.96 \%, 30.68 \%$ and $29.30 \%$ after $\{14-6-14$ GS + chase water\}, \{14-6-14 GS + PHPA + chase water $\}$ and \{14-6-14 GS + PHPA + SiO2 chase water $\}$ flooding respectively. Tertiary recoveries of $15-19 \%$ were achieved, depending on injected fluid composition. Experimental data were history matched via CMOST tool to achieve good matching of simulated results. The CMG flooding simulator provides a holistic approach to investigate oil displacement profiles, assess flooding recovery capabilities with near-accuracy and predict the feasibility of proposed chemical EOR projects.
\end{abstract}

\section{Introduction}

The importance of subterranean petroleum hydrocarbons as a dependable energy resource has intensified on global scale owing to the ever-increasing consumption of crude oil and/or associated products in industrial, household, transportation and technological applications [1,2]. This has led to the exploration and production of oil from complicated reservoir formations, wherein problems such as low permeability, heterogeneity and less accessibility persist during extraction processes. The initial stage encompasses the application of primary and secondary recovery techniques to produce one-thirds to nearly one-half of the original oil in place (OOIP) by natural drive and water/gas injection. Enhanced oil recovery (EOR) methods have attracted widespread attention in the last few decades to attain optimized production of residual oil trapped by alteration of reservoir fluid properties after conventional recovery [3,4]. Surfactant flooding is a promising EOR technique employed by the production sector since 1970s decade $[5,6]$. This type of oil recovery functions by allowing surfactants or "surface-active agents" to adsorb onto the interface of oil/water, thereby decreasing interfacial free energy and increasing dimensionless capillary number [5-7]. Polymer improves the viscosity of displacing (injected) fluid to reduce the mobility ratio between water and oil [8,9]. Furthermore, polymer addition increases the viscous force perpendicular to oil-water interface and responsible for pushing the residual oil towards the production well $[8,9]$. When this force exceeds the capillary forces holding crude oil within rockpores, residual oil detaches from the rock surface and mobilizes forward with increasing sweep efficiencies. Nanoparticles, in conjunction with surfactant and polymer, adsorb onto interfaces to enhance the mechanical barrier onto displaced crude oil surfaces and produce impulsive emulsions with improved crude oil attracting 
ability [10,11]. A pivotal aspect of chemical EOR lies in proper screening and optimization of displacing fluid, keeping in mind the effectiveness as well as cost-profitability of the method employed [12]. Hence, surfactant, polymer and/or nanoparticle in chemical fluid must be introduced to create a forward-moving oil bank within porous rock formations, which can significantly improve the oil recovery and maintain pressure gradient during chemical fluid $+/$ chase water injection.

Simulation studies are important to assess the flooding performance of injected chemical fluids, and predict how oil displacement will occur under specified reservoir/fluid conditions [13,14]. Prior to simulation, the technological feasibility of different EOR routes are tested by experimental investigations [14,15]. Such studies provide useful input information to allow the simulator to identify reservoir parameters, predict recovery and testing the effectiveness of different EOR projects with similar components [13-16]. The current industry is involved in the application of realistic chemical flood simulators like STARS by Computer Modelling Group (CMG), UTCHEM by the University of Texas at Austin (UT Austin), REVEAL by Petroleum Experts (Petex), and ECLIPSE by Schlumberger (SLB). The physics associated with fluid properties' evaluation differ in each type of reservoir simulator [17-19]. UTCHEM is a compositional simulator capable of simulating different types of EOR processes owing to the provision of four different phases (gas, aqueous, oil, microemulsion) and incorporation of advanced numerical concepts [20]. REVEAL, a full field reservoir expert, is similar to UTCHEM with surfactant phase behavior and mobility control options, permeability reduction and polymer degradation parameters [21]. However, this tool is not well known among professionals and engineers in production areas and the existence of a fourth phase i.e. microemulsion may cause problems in field studies $[17,20,21]$. As per UTCHEM and REVEAL, the presence of a microemulsion phase is a key parameter to model displacement efficiency, in spite of the fact that microemulsion properties are not generally measured in pilot tests and field operations [18-21]. Both ECLIPSE and STARS do not consider microemulsion phase as contributor to flooding simulation and represent oil displacement behavior via analyses of relative permeability curves for experimental results $[17,22,23]$. However, ECLIPSE software, though common in the industry, does not encompass the technical functionalities such as salinity effects, adsorption, polymer concentration mixing, multi-component EOR, shear thickening and degradation regimes required for accurate modelling [22]. Another powerful flooding simulator is CMG, which is capable of modeling flooding results and manage complex behavior of oil-chemical-water systems in laboratory-scale and field-scale porous media $[24,25]$. Goudarzi and other researchers [17,19] assessed the performance of different reservoir simulators and developed an EOR benchmark to improve chemical design for field-scale as well as lab-scale operations. Pandey et al. [26] employed CMG-STARS for coreflood modelling experiments and investigated flow parameters that could be subsequently used in pilot field tests. Kazempour and others [18] investigated the validity of multi-phase component EOR systems in detail, and identified the dynamic behavior of fluid components existing within core-flood model. Tunnish et al. [27] successfully matched experimental flooding results using CMG to effectively tune relative permeability curves and predict the chemical fluid's ability to produce in-situ crude oil. Dahbag et al. [28] reported the performance of ionic liquid/surfactant flooding during chemical oil recovery processes, and found the results can be used to predict future scenarios. CMG tool is reliable and instrumental in evaluating the potential of conventional and modern EOR methods [17-19,24-28].

In this article, a series of flooding experiments were performed to investigate the secondary and tertiary oil recoveries using surfactant, surfactant-polymer and surfactant-polymer-nanoparticle slugs. Initially, physicochemical behavior of designed fluids were evaluated by a series of experimental studies. A Cartesian grid model was developed using CMG-STARS software, and parameters such as rock-fluid properties, interfacial tension, viscosity, adsorption and injector/producer geometry were entered in the simulation model. Thereafter, the experimental results obtained in the laboratory were history-matched for specified builder and injection pattern/time was set with CMOST tool. Emphasis is put on the injected fluid composition, flow rate and flooding period. Using detailed methodical approach to identify and predict well-matched recovery data, produced recovery data were optimized with minimal error as compared to laboratory results. This model is useful to simulate surfactant/polymer/particle behavior on core-scale, and optimize brine/chemical flooding from functional viewpoint. 


\section{Experimental and Simulation}

\section{Materials}

The surfactant employed in this study is N,N'-bis(dimethyltetradecyl)-1,6-hexanediammonium bromide (abbreviated as 14-6-14 GS) with molecular weight of $726 \mathrm{~g} / \mathrm{mol}$. This gemini surfactant was synthesized and characterized in our earlier papers $[29,30]$. Partially hydrolysed polyacrylamide (PHPA), a water-soluble polymer was purchased from SNF Floerger, SNF SAS, ZAC de Millieux, Andrézieux, France. It has molecular weight of $2.1 \times 10^{7} \mathrm{~g} / \mathrm{mol}$ with $26.4 \%$ hydrolysis. Aqueous polymer solutions were prepared in accordance with the American Petroleum Institute: Recommended practices for evaluation of polymers used in EOR operations (API RP 63). Silica $\left(\mathrm{SiO}_{2}\right)$ nanopowder $(5-15 \mathrm{~nm})$ was obtained from Merck Industries. Sandstone core employed in flooding experiments was procured from Kalol field in Gujarat, India. Crude oil sample has total acid number (TAN) of $0.044 \mathrm{mg} \mathrm{KOH} / \mathrm{g}$, kinematic viscosity of $6.147 \times 10^{-5} \mathrm{~m}^{2} / \mathrm{s}$ and $23.55^{\circ}$ API gravity at $303 \mathrm{~K}$. It was procured from Ahmedabad oil field, ONGC Asset, India. Double distilled water was extracted from distillation apparatus in our laboratory.

\section{Physicochemical evaluation tests}

Wettability behavior of 14-6-14 GS was investigated by contact angle studies with the help of Kruss DSA25 Drop Shape Analyzer. Adsorption behavior of gemini surfactant molecules onto sand surface was conducted by UV spectrometric analyses to determine the amount of 14-6-14 GS adsorbed per weight sand (in mg/g). Interfacial tension experiments were performed by analyzing rotating crude oil drop profile in continuous surfactant/polymer/nanoparticle containing aqueous solution with the help of spinning drop SVT20 tensiometer (Dataphysics). Viscosity values of aqueous chemical fluids were measured using cup and bob geometry in Bohlin Gemini 2 Rheometer instrument at $303 \mathrm{~K}$. The obtained experimental results serve as input-data during simulation studies.

\section{Flooding procedure}

The experimental flooding apparatus (Porous Material Inc.) consists of core-holder, positive displacement pump, chemical slug injectors and measuring cylinder for collecting effluent samples. Sandstone core with $8.74 \mathrm{~cm}$ length and $3.66 \mathrm{~cm}$ diameter was initially saturated with $1.0 \% \mathrm{NaCl}$ brine for $72 \mathrm{~h}$ to saturate the cores; and obtain porosity values in the range $17-18 \%$. The core sample showed permeabilities in the range 350-400 milliDarcies $(\mathrm{mD})$. When placed within core-holder apparatus, a confining pressure of 1000-1200 psi was employed to hold the core in vertical position. Crude oil was injected into the pores to displace aqueous phase, until irreducible saturation state was achieved. This was followed by an ageing period of 6 days to obtain an oil-saturated reservoir model in the laboratory. Secondary flooding was investigated by brine flooding at the rate of $10 \mathrm{ml} / \mathrm{h}$ to recover a fraction of crude oil. When water cut percentage exceeds [?] 95\%, chemical aqueous fluid containing surfactant $+/$ polymer $+/$ nanoparticle was flooded at $5-10 \mathrm{ml} / \mathrm{h}$ rate to sweep residual oil during EOR. Finally, chase water was injected at the same flow-rate to maintain pressure drop for favorable oil displacement. Effluent liquid produced during secondary and tertiary recovery studies were collected in graduated cylinders.

\section{Simulation methodology}

The STARS simulator package in CMG is widely employed compositional tool in the petroleum industry, with the capacity to develop reservoir models [24-27]. A Cartesian grid system with specified divisions along $\mathrm{X}$-axis, and the developed model was simulated to match flooding history data using CMOST analysis tool. Prior to running the STARS simulation for aqueous flooding model and subsequent history-matching of experimental recovery data, the following assumptions were made to obtain accurate findings [31,32]:

1. The reservoir initially consists of two phases, namely, crude oil and water.

2. The amount of free gas/solvent gas in the core model is assumed as zero.

3. A grid-based core model is considered, with uniform properties and no geological complexities/heterogeneities.

4. Fluid flow in radial direction is negligible as compared to that in axial direction. 
5. Salinity effect on phase behavior is ignored.

6. Chemical reactions do not occur.

7. Oil and water flowing through porous media obeys the Darcy's Law.

Porosity, permeability and crude oil properties were introduced as input data for reservoir characterization. In recent years, the need to develop appropriate flooding model has paved the way to make informed decisions during chemical fluid selection/optimization and field implementation [33-35]. Druetta and co-workers [35] developed a flooding simulator to investigate EOR properties of different chemical fluid compositions. Arhuoma et al. [36] found that CMG simulation model is useful to determine displacement phenomena governing flooding behavior, depending on injection fluid type. The effectiveness of numerical simulation studies on chemical flooding showed far-reaching consequences during oilfield applications, as evident from the findings of earlier papers [34,37]. This kind of grid-based model helps in understanding fluid flow behavior prior to injection; as well as achieve a sufficiently robust numerical model $[33,35,36]$. Table 1 presents the core and fluid properties employed in STARS model.

Table 1. Core model and fluid parameters for flooding simulations.

\begin{tabular}{ll}
\hline Core ID & Sandstone \\
\hline Core type & Berea sandstone \\
Core diameter & $3.66 \mathrm{~cm}$ \\
Core length & $8.74 \mathrm{~cm}$ \\
Bulk volume & $91.95 \mathrm{~cm}^{3}$ \\
Porosity & $17-18 \%$ \\
Permeability & $350-400 \mathrm{mD}$ \\
Crude oil Gravity & $23.55^{\circ} \mathrm{API}$ \\
Crude oil viscosity & $10.94 \mathrm{cP}$ \\
Crude oil API & $23.55^{\circ} \mathrm{API}$ \\
Formation Water viscosity & $0.8177 \mathrm{cP}$ \\
Initial reservoir pressure & $101 \mathrm{kPa}$ \\
Temperature & $303 \mathrm{~K}$ \\
\hline
\end{tabular}

\section{Governing equations for Multi-phasic reservoir modeling}

CMG-STARS is a finite difference numerical tool that describes mathematical equations for fluid flow in a petroleum reservoir. In multiphase flow equations, the simulation model is governed by the conservation of mass, energy and momentum. These functions relate conservation equations with an elementary volume or specified region of interest; wherein each component of volumetric change is related to the fluids entering or leaving the system [38,39]. This includes the material balance equations, Darcy's law, relative permeability correlations, capillary pressure equations, and phase equilibrium equations in two- and three-phase porous media [39-41]. The conservation law states that the conserved quantity within a volume or at a point depends on the net rate of fluids that flow in and out of the volume (or region). With the depiction of an appropriate set of initial/boundary conditions, the governing models are applied to develop an understanding of simultaneous flow of two or more fluid phases. The conservation equation for mass is presented for a flowing and/or adsorbed component ' $i$ ' within the system as Eq. (1):

$\frac{\partial}{\partial t}\left[V_{f}\left(\rho_{w} S_{w} w_{i}+\rho_{o} S_{o} x_{i}+\rho_{g} S_{g} y_{i}\right)+V_{v} \operatorname{Ad}_{i}\right]=\sum_{k=1}^{n_{f}}\left[T_{w} \rho_{w} w_{i} \Delta \Phi_{w}+T_{o} \rho_{o} x_{i} \Delta \Phi_{o}+T_{g} \rho_{g} y_{i} \Delta \Phi_{g}\right]+$ $V \sum_{k=1}^{n_{r}}\left(s_{\mathrm{ki}}^{\prime}-s_{\mathrm{ki}}\right) r_{k}+\sum_{k=1}^{n_{f}}\left[\phi D_{\mathrm{wi}} \rho_{w} \Delta w_{i}+\phi D_{\mathrm{oi}} \rho_{o} \Delta \xi_{i}+\phi D_{\mathrm{gi}} \rho_{g} \Delta y_{i}\right]+\rho_{w} q_{\mathrm{wk}} w_{i}+\rho_{o} q_{\mathrm{ok}} x_{i}+\rho_{g} q_{\mathrm{gk}} y_{i}+$ $\delta_{\mathrm{iw}} \sum_{k=1}^{n_{f}} \rho_{w} \mathrm{qaq}_{\mathrm{wk}}(1)$

where, $\frac{\partial}{\partial t}\left[V_{f}\left(\rho_{w} S_{w} w_{i}+\rho_{o} S_{o} x_{i}+\rho_{g} S_{g} y_{i}\right)+V_{v} \mathrm{Ad}_{i}\right]$ is the time-derivative for material accumulation. The total fluid volume and void volume are represented by terms, $V_{f}$ and $V_{v}$ respectively. In above relation, $w_{i}$, $x_{i}$, and $y_{i}$ refer to mole fraction of component ' $i$ 'in water, oil and gas respectively, whereas $\rho$ and $S$ stand 
for density and saturation of different phases. $\left[T_{w} \rho_{w} w_{i} \Delta \Phi_{w}+T_{o} \rho_{o} x_{i} \Delta \Phi_{o}+T_{g} \rho_{g} y_{i} \Delta \Phi_{g}+\phi D_{\mathrm{wi}} \rho_{w} \Delta w_{i}+\right.$ $\left.\phi D_{\mathrm{oi}} \rho_{o} \Delta \xi_{i}+\phi D_{\mathrm{gi}} \rho_{g} \Delta y_{i}\right]$ is the flow term for component ' $i$ ' . [ $\left[\rho_{w} q_{\mathrm{wk}} w_{i}+\rho_{o} q_{\mathrm{ok}} x_{i}+\rho_{g} q_{\mathrm{gk}} y_{i}\right]$ is well source/sink term, and $V \sum_{k=1}^{n_{r}}\left(s_{\mathrm{ki}}^{\prime}-s_{\mathrm{ki}}\right) r_{k}$ stands for the reaction source/sink term for component ' $i$ '. For water component, $\sum_{k=1}^{n_{f}} \rho_{w} \mathrm{qaq}_{\mathrm{wk}}$ is aquifer source/sink term wherein $q a q_{w k}$ represents the volumetric flow rate through the block face $k$ to/from adjacent aquifer.

$T$ is the component transmissibility between two regions/points, which accounts for cross-sectional area, distance between the elementary volumes, and fluid permeability. Eq. (2) depicts the relation between volumetric flow rate, $v$ and transmissibility, $T$, as:

$v_{j}=T\left(\frac{k_{\mathrm{rj}}}{\mu_{j} r_{j}}\right) \Phi_{j}(2)$

In this equation, the term ' $j$ ' can be applied to different phases, i.e. water $(w)$, oil $(o)$ and gas $(g) . \Delta \Phi_{\vartheta}$ represents potential difference for phase ' $j$ ', and it may be either positive or negative, depending on the inflow/outflow of fluid component. $r_{j}$ is phase resistance factor, $k_{r j}$ is relative permeability and $\mu_{\mathrm{j}}$ is viscosity of phase $j$. Component dispersibility in water, oil, and gas phases are shown by $D_{w i}, D_{o i}$, and $D_{g i}$. The well rate $\left(q_{j k}\right)$ of any phase ' $j$ ' in the layer ' $k$ ' is shown in Eq. (3):

$q_{\mathrm{jk}}=I_{\mathrm{jk}}\left(p_{\mathrm{wfk}}-p_{k}\right)(3)$

where, $p_{w f k}$ is wellbore pressure, $p_{k}$ is pressure existing within volume and $I_{j k}$ refers to phase index. The phase index property of the system depends on various factors such as geometry, permeability, layer thickness, and skin factor. Therefore, individual changes in each component contribute toward conservation studies for mass. Total energy of the material volume is an important field of research analysis, which has significant repercussion in defining fluid flow behavior. During CMG simulation, the rock volume does not change, and the internal energy of the rock remains constant. The energy conservation equation is shown in Eq. (4) as:

$\frac{\partial}{\partial t}\left[V_{f}\left(\rho_{w} S_{w} U_{w}+\rho_{o} S_{o} U_{o}+\rho_{g} S_{g} U_{g}\right)+V_{v} c_{s} U_{s}+V_{r} U_{r}\right]=\sum_{k=1}^{n_{f}}\left[T_{w} \rho_{w} H_{w} \Delta \Phi_{w}+T_{o} \rho_{o} H_{o} \Delta \Phi_{o}+T_{g} \rho_{g} H_{g} \Delta \Phi_{g}\right]+$ $\sum_{k=1}^{n_{f}} K T+\rho_{w} q_{\mathrm{wk}} H_{w}+\rho_{o} q_{\mathrm{ok}} H_{o}+\rho_{g} q_{\mathrm{gk}} H_{g}+V \sum_{k=1}^{n_{r}} H_{\mathrm{rk}} r_{k}+H L_{o}+H L_{v}+H L_{c}+\sum_{k=1}^{n_{f}}\left(H A_{\mathrm{CV}}+H A_{\mathrm{CD}}\right)_{k}(4)$

In the above equation, $\frac{\partial}{\partial t}\left[V_{f}\left(\rho_{w} S_{w} U_{w}+\rho_{o} S_{o} U_{o}+\rho_{g} S_{g} U_{g}\right)+V_{v} c_{s} U_{s}+V_{r} U_{r}\right]$ is the time-derivative for energy accumulation, and $U_{j}$ is the internal energy of the rock system. It is primarily influenced by two factors, namely, temperature and phase composition. $H_{j}$ denotes the enthalpy of the respective phases. Reaction source/sink term for energy is represented by $V \sum_{k=1}^{n_{r}} H_{\mathrm{rk}} r_{k}$, wherein $H_{r k}$ and $r_{k}$ stand for enthalpy and volumetric rate of reaction in layer ' $k$ 'respectively. $H L_{o}, H L_{v}$ and $H L_{c}$ represents the total heat transfer rate, heat transfer rate for convection model and constant heat transfer model respectively. $\sum_{k=1}^{n_{f}}\left(H A_{\mathrm{CV}}+H A_{\mathrm{CD}}\right)_{k}$ describes the aquifer source/sink term for energy, wherein $H A_{C V}$ and $H A_{C D}$ represent respective rates of heat transfer via convection; and conduction to/from adjacent aquifer. $\left[T_{w} \rho_{w} H_{w} \Delta \Phi_{w}+T_{o} \rho_{o} H_{o} \Delta \Phi_{o}+T_{g} \rho_{g} H_{g} \Delta \Phi_{g}+K T\right]$ represents the energy term for flow between two regions, and $\left[\rho_{w} q_{\mathrm{wk}} H_{w}+\rho_{o} q_{\mathrm{ok}} H_{o}+\rho_{g} q_{\mathrm{gk}} H_{g}\right]$ is the well source/sink term for energy.

CMG-STARS employs various equations to generate relative permeability curves, which convey rock-fluid interactions in porous media flow studies. Corey's correlation is an important alternative to calculate relative permeability curves, particularly in situations wherein displacing/displaced fluid properties are not available in detail [42-44]. This behavior is described in Eqs. (5), (6), (7), and (8) as:

$$
\begin{aligned}
& K_{\mathrm{rw}}=K_{\text {rwiro }}\left(\frac{S_{w}-S_{\text {wcrit }}}{1.0-S_{\text {wcrit }}-S_{\text {oirw }}}\right)^{N_{w}}(5) \\
& K_{\text {row }}=K_{\text {rocw }}\left(\frac{S_{o}-S_{\text {orw }}}{1.0-S_{\text {wcon }}-S_{\text {orw }}}\right)^{N_{\text {ow }}}(6) \\
& K_{\text {rog }}=K_{\text {rogcg }}\left(\frac{S_{l}-S_{\text {org }}-S_{\text {wcon }}}{1.0-S_{\text {gcon }}-S_{\text {org }}-S_{\text {wcon }}}\right)^{N_{\mathrm{og}}}(7) \\
& K_{\text {rg }}=K_{\text {rgcl }}\left(\frac{S_{g}-S_{\text {gcrit }}}{1.0-S_{\text {gcrit }}-S_{\text {oirg }}-S_{\text {wcon }}}\right)^{N_{g}}(8)
\end{aligned}
$$


$K_{r w}, K_{\text {row }}, K_{\text {rog }}$ and $K_{r g}$ refer to respective values of water phase relative permeability for water-oil table, oil phase relative permeability for water-oil table, liquid phase relative permeability for liquid-gas table, and gas phase relative permeability for liquid-gas table. Different saturation terms were employed to characterize wetting characteristics of reservoir rock [43,44]. It is to be noted that $K_{\text {rocw }}$ is $K_{\text {ro }}$ at connate water saturation, $K_{r g c l}$ is $K_{r g}$ at connate liquid saturation, $K_{r w i r o}$ is $K_{r w}$ at irreducible oil saturation,and $K_{\text {rogcg }}$ is $K_{\text {rog }}$ at connate gas saturation. Connate water saturation, critical water saturation, irreducible oil saturation for water-oil table, and residual oil saturation for water-oil table are represented by $S_{w c o n}, S_{w c r i t}, S_{\text {oirw }}$ and $S_{\text {orw }}$ respectively. Irreducible oil saturation, residual oil saturation, connate gas saturation and critical gas saturation are depicted by respective terms $S_{\text {oirg }}, S_{\text {org }}, S_{\text {gcon }}$ and $S_{\text {gcrit }}$ for liquid-gas table. $N_{w}, N_{\text {ow }}, N_{\text {og }}$ and $N_{g}$ are exponent terms determined from relative permeability curves. Equations (5) and (6) describe the water-oil permeability table, whereas equations (7), (8) are used to generate liquid-gas relative permeability data. Alterations occurring within physicochemical properties of reservoir fluids due to presence of chemicals i.e. surfactant, polymer and/or nanoparticle lead to varying fluid flow profiles during EOR. Interpolation of relative permeability curve is performed by corresponding to relative permeability datasets in-between high and ultralow IFT conditions $[45,46]$. The interpolated relative permeability data is described as function of dimensionless parameters, as shown in Eqs. (9), (10) and 11):

$k_{\mathrm{rw}}=k_{\mathrm{rwA}} \cdot\left(1-\operatorname{ratn}^{\mathrm{WCRV}}\right)+k_{\mathrm{rwB}} \cdot \operatorname{ratn}^{\mathrm{WCRV}}(9)$

$k_{\mathrm{ro}}=k_{\mathrm{roA}} \cdot\left(1-\operatorname{ratn}^{\mathrm{OCRV}}\right)+k_{\mathrm{roB}} \cdot \operatorname{ratn}^{\mathrm{OCRV}}(10)$

$k_{\mathrm{rg}}=k_{\mathrm{rgA}} \cdot\left(1-\operatorname{ratn}^{\mathrm{GVRV}}\right)+k_{\mathrm{rgB}} \cdot \operatorname{ratn}^{\mathrm{GCRV}}(11)$

In the above equations, ratw and ratn refer to interpolation parameters with values ranging between zero and unity. The curvature interpolation parameters are represented by $W R C V, O C R V$, and GCRV, with the default value of one. Furthermore, the interpolation parameters are related to the capillary number as shown in Eq. (12) and Eq. (13) as follows:

$r a t w=\frac{\left(N_{c}\right)-D T R A P W A}{D T R A P W B-D T R A P W A}(12)$
ratn $=\frac{\left(N_{c}\right)-D T R A P N A}{D T R A P N B-D T R A P N A}(13)$

where, $\mathrm{N}_{\mathrm{c}}$ is the capillary number, whereasDTRAPWA and DTRAPNA describe interpolation parameters for high IFT value (low $\mathrm{N}_{\mathrm{c}}$ condition) and ultralow IFT value (favorably high $\mathrm{N}_{\mathrm{c}}$ condition) respectively, for wetting phase. On the contrary, DTRAPNA and DTRAPNB are similar interpolation terms for the non-wetting phase. Relative permeability plot analysis is important during CMG-STARS modelling studies for accurate investigation of fluid-rock interactions and flooding performance of injection fluids.

1. Results and Discussion

2. Experimental investigations

3. Rock-wetting characteristics of 14-6-14 GS

Wettability alteration characteristics was investigated by sessile drop analyses of aqueous surfactant fluid onto crude oil-saturated sandstone rock. Figs. 1(a) and 1(b) show the variation of contact angle with time. At initial time $(\mathrm{t}=0)$, contact angle was measured as $102.8^{\circ}$, confirming the intermediate wet nature of rock surface. For sandstone rock, contact angle progressively reduced to $72.6^{\circ}, 61.9^{\circ}, 50.9^{\circ}, 32.1^{\circ}$ and $14.2^{\circ}$; at the end of $30 \mathrm{~s}, 60 \mathrm{~s}, 120 \mathrm{~s}, 240 \mathrm{~s}$ and $480 \mathrm{~s}$ respectively. This trend is indicative of "spreading" of aqueous chemical fluid and "detachment" of crude oil molecules from rock surface [47]. Rock-wetting process is mainly dependent on rock morphology, inter-ionic electrostatic interactions and attractive and attractive/hydrophobic interactions among 14-6-14 GS molecules and crude oil components. As time elapses, surfactant molecules gradually destabilize the ordered arrangement of previously adsorbed oil molecules and spread onto the rock substrate. Hence, 14-6-14 GS possess the capability to favorably "wet" oil-saturated rock and mobilize entrapped crude oil within reservoir formations effectively. 


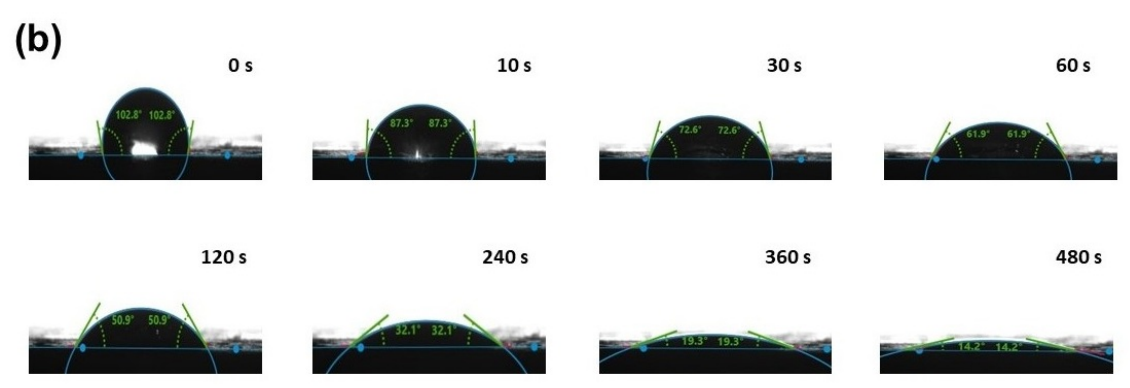

Fig. 1(a). Dynamic contact angle values expressed a function of time for 0.10\% 14-6-14 GS system; (b) Sessile drop profiles of surfactant fluid at different time intervals for sandstone rock at $303 \mathrm{~K}$.

\section{Surfactant adsorption behavior}

Surfactant adsorption is a major problem encountered during chemical EOR owing to material losses observed within reservoir pore-throats. Adsorption profile, obtained from UV spectroscopic analysis as a function of 14-6-14 GS concentration for sandstone, is presented in Fig. 2. At low 14-6-14 GS concentrations (> CMC), surfactant molecules begin to form aggregates/micelles and are subsequently attracted to dispersed rock particle charge as electrical double layer [48,49]. This ultimately leads to a sharp increase in adsorbed surfactant. With further addition, 14-6-14 GS dimer molecules start to occupy active "adsorption" sites; and repel previously adsorbed micelles or aggregates [48]. Consequently, rock adsorption for 14-6-14 GS increased gradually with increasing concentration. At this stage, solid surface shows a very slow increasing trend for 14-6-14 GS adsorption density profiles owing to nearly complete saturation of rock-liquid interfaces with surfactant dimer molecules. The main influencing factor responsible for 14-6-14 GS adsorption is the formation of an ionic or electrostatic pairing bond between cationic head-groups of surfactant molecules and negatively charged rock surface [49]. However, attractive forces such as electrostatic pairing between surfactant head and charged rock surface, dispersive forces, hydrophobic forces among adsorbed and free surfactant molecules, hydrogen bonding and covalent interactions also aid in enhancing the adsorption behavior of surfactant species $[48,49]$.

Fig. 2. Adsorption density onto sand surface for 14-6-14 GS at $303 \mathrm{~K}$.

Experimental data for rock adsorption was investigated by Langmuir and Freundlich isotherms. The model parameters obtained by fitting experimental data with adsorption theories are depicted in Table 2. Though both isotherms have their respective behavioural traits and applications, a careful evaluation of adsorption density versus surfactant concentration plots with these theories may help in understanding the molecular arrangement of adsorbed 14-6-14 GSs onto sandstone rock. Langmuir model assumes that surfactant molecules form a single layer onto adsorbent rock surfaces, wherein Freundlich model suggests a multiple layer stacking arrangement of adsorbed surfactant species [50]. Langmuir model exhibited better results as compared to Freundlich adsorption model, which was evident from larger values of coefficient of determination $\left(\mathrm{R}^{2}\right)$. Furthermore, smaller values of chi-square statistic $\left(\chi^{2}\right)$ were obtained during Langmuir isotherm fitting, which further corroborated our inclination to the Langmuir isotherm model to predict surfactant adsorption data. Therefore, monomolecular layer of adsorbed 14-6-14 GS molecules is proposed with no stacking behavior during rock adsorption studies.

Table 2. Langmuir and Freundlich model parameters obtained by fitting experimental adsorption data

\begin{tabular}{lllll}
\hline Gemini surfactant & $\mathbf{1 4 - 6 - 1 4}$ GS & $\mathbf{1 4 - 6 - 1 4}$ GS & $\mathbf{1 4 - 6 - 1 4}$ GS & 14-6-14 GS \\
\hline \multirow{2}{*}{ Langmuir } & Adsorption parameters & Adsorption parameters & Adsorption parameters & Adsorption \\
& $\mathrm{K}_{\mathrm{L}}$ & $\mathrm{Q}_{\text {sat }}(\mathrm{mg} / \mathrm{g})$ & $\boldsymbol{\chi}^{\mathbf{2}}$ & $\mathbf{R}^{\mathbf{2}}$ \\
& 4.0619 & 3.2988 & 0.0217 & 0.9128
\end{tabular}




\begin{tabular}{lllll}
\hline Gemini surfactant & $\mathbf{1 4 - 6 - 1 4}$ GS & $\mathbf{1 4 - 6 - 1 4}$ GS & $\mathbf{1 4 - 6 - 1 4}$ GS & 14-6-14 GS \\
\hline Freundlich & Qsat*KF $^{*}(\mathrm{mg} / \mathrm{g})$ & $\mathbf{1 / n}$ & $\chi^{2}$ & $\mathbf{R}^{\mathbf{2}}$ \\
& 3.7556 & 0.5995 & 0.0349 & 0.8601 \\
\hline
\end{tabular}

\section{Interfacial tension experiments}

Evaluation of IFT is a pivotal parameter to evaluate the performance of chemical fluid to recover tertiary crude oil. Aqueous surfactant solutions were prepared at concentrations ranging between $0.05 \%$ and $0.35 \%$, wherein silica particle dosages were varied at $0.01-0.10 \%$ in aqueous nanoparticle dispersions. Fig. 3(a) and 3(b) depicts the variation of IFT with surfactant concentration at $303 \mathrm{~K}$. It was observed that IFT decreased with increasing surfactant/nanoparticle concentrations up to a critical limit. In the absence of any surface-active species, IFT value was found to be $18.2 \mathrm{mN} / \mathrm{m}$. GS exhibited ultralow IFT owing to their unique molecular structure and capability to self-aggregate at low concentrations. IFT decreased significantly with values of $0.1127 \mathrm{mN} / \mathrm{m}$ and $0.0594 \mathrm{mN} / \mathrm{m}$ at $0.05 \%$ and $0.10 \%$ 14-6-14 GS respectively. 14-6-14 GS molecules form micelles; and arrange as mixed micellar phase existing at oil-aqueous interfaces [51,52]. At $0.10 \%$ concentration, the interface was completely saturated with 14-6-14 GS molecules, which is evident from minima value of IFT. Beyond this concentration, a slight increase in IFT was observed due to variation of distribution of adsorbed molecules/micelles, resulting in slightly higher rate of desorption as compared to surfactant adsorption process. Once at the interface, 14-6-14 GS molecules readjust and orient themselves such that the two tail groups point towards crude oil phase in order to achieve equilibrium conditions with minimum interfacial energy and favorable oil-attracting capacity [47,52]. Like surfactant, nanoparticles adsorbed along interface of oil and aqueous phases; and favorably improved interfacial activity. The IFT decreased from $18.2 \mathrm{mN} / \mathrm{m}$ to $~ 6.0 \mathrm{mN} / \mathrm{m}$ during $\mathrm{SiO}_{2}$ addition. It is evident that nanoparticles do not achieve ultralow IFT values due to less efficient adsorption activity. However, nanoparticle strengthen the mechanical barrier effect, which ensure improved oil mobilization ability [53].

Fig. 3. Oil-aqueous IFT profiles presented as a function of: (a) 14-6-14 GS concentration, and (b) $\mathrm{SiO}_{2}$ nanoparticle concentration.

In this section, surfactant/polymer/nanoparticle fluids were placed in contact with oil to identify synergistic associations among interacting mixed species. Fig. 4 shows the IFT behavior of 14-6-14 GS +/ PHPA aqueous fluids in the presence and absence of silica $\left(\mathrm{SiO}_{2}\right)$. Surfactant-polymer fluids exhibited greater values of IFT in comparison to pure surfactant solutions. PHPA addition favors inter-polymer and intra-polymer interactions, thereby reducing their exposure to water [54]. This reduces the number of adsorbed 14-614 GS molecules in mixed micelles/aggregates in solution and lower surfactant adsorption at liquid-liquid interfaces. The electrostatic repulsive forces between surfactant dimer head-groups increases significantly during polymer addition. Polymer chains diffuse to adsorption sites and cause significant variation in intermolecular arrangement, resulting in IFT increase [54,55]. However, polymer addition enhances oil mobility to improve the sweep efficiency of displaced crude oil.

Nanoparticle addition showed better activity in terms of reduced IFT, which is attributed to their favorable adsorption at oil-aqueous interfaces and reduction in interfacial energy barrier [53,56]. However, this behavior was observed until a favorable $\mathrm{SiO}_{2}$ concentration, referred to as critical concentration. For surfactant solutions, IFT was reduced from $0.0594 \mathrm{mN} / \mathrm{m}$ to $0.0194 \mathrm{mN} / \mathrm{m}$ at $0.030 \% \mathrm{SiO}_{2}$. In case of surfactantpolymer solutions, critical NP dosage of $0.025 \%$ was obtained with IFT minima of $0.0318 \mathrm{mN} / \mathrm{m}$. The critical NP concentration obtained in case of surfactant-polymer-nanoparticle (SPN) fluids is lower (0.025 wt. \%) as compared to that obtained for surfactant fluids $(0.030$ wt. \%). Beyond this limit, IFT was observed to increase gradually owing to improved steric effect in the presence of higher concentration species [56,57]. This indicated desorption of interacting molecules/particles from the interface to the bulk solution phase and consequent transition of mixed micelles to super micelles or vesicles [56,57]. SPN fluids are able to recover oil with IFT values in the desired optimal range and sweep crude oil with greater efficacy as 
compared to surfactant-nanoparticle and surfactant formulations. Henceforth, interfacial behavior of SPN aqueous solutions contribute beneficially in EOR studies.

Fig. 4. Interfacial tension plots for 14-6-14 GS and \{14-6-14 GS + PHPA $\}$ systems, presented as a function of silica concentration at $303 \mathrm{~K}$.

\section{Influence of polymer/nanoparticle on fluid rheology}

An EOR fluid must possess favorable rheological properties to achieve favorable displacement of crude oil through porous rock formations. The influence of addition of surfactant (14-6-14 GS), polymer (PHPA) and nanoparticle $\left(\mathrm{SiO}_{2}\right)$ on the viscosity of chemical fluids are studied to identify flow behavior and predict oil mobilization ability. Figs. 5(a), 5(b) and 5(c) show plots of viscosity versus concentration at shear rate of $10 \mathrm{~s}^{-1}$. It is evident that apparent viscosity increases with increasing concentration. Aqueous chemical fluids showed shear thinning or pseudoplastic flow behavior, which is considered as desirable attributes to achieve good injectivity and oil mobilization control. Fig. 5(d) shows the viscosity versus shear stress plots for different aqueous fluid compositions at $303 \mathrm{~K}$. With application of increasing shear rate, hydrophobic associations are weakened which decrease the strength of inter-molecular and intra-molecular interactions. Viscosity of aqueous solution was observed to be $4.93 \mathrm{mPa} . \mathrm{s}$ at $0.02 \%$ 14-6-14 GS concentration, which subsequently increased to $6.63 \mathrm{mPa} . \mathrm{s}$ at $0.05 \%, 11.24 \mathrm{mPa} . \mathrm{s}$ at $0.10 \%, 13.84 \mathrm{mPa} . \mathrm{s}$ at $0.20 \%$ and 14.29 $\mathrm{mPa} . \mathrm{s}$ at $0.35 \%$ concentrations (refer to Fig. 5(a)). With increase in 14-6-14 GS concentration, surfactant molecules form super-micelles or vesicles in bulk solution, which reduces the available "free" volume and enhances fluid viscosity. Addition of polymer as well as nanoparticle also exhibited similar behavior in terms of viscosity for $0.10 \%$ 14-6-14 GS containing fluids. With addition of $0.05 \%$ PHPA, viscosity increased to value as high as $27.69 \mathrm{mPa} . \mathrm{s}$, as depicted in Fig. 5(b). This is attributed to the increased degree of entanglement of polymer chains and formation of a network structure consisting of "larger" mixed micelle associations [58]. Fig. 5(c) shows further increase in aqueous solution viscosity in the presence of $\mathrm{SiO}_{2}$ nanoparticle due to their ability to effectively strengthen the mechanical barrier (electrostatic repulsion + steric effects) around dispersed micelles/aggregates formed within $\left\{14-6-14 \mathrm{GS}+\mathrm{PHPA}+\mathrm{SiO}_{2}\right\}$ solution $[56,59]$. This leads to more pronounced network structure with longer mixed micelle entanglements and consequent increase in viscosity. Surfactant-polymer-nanoparticle (SPN) fluids showed a sharp increase in viscosity (42.82 $\mathrm{mPa} . \mathrm{s})$ until concentration limit of $0.025 \% \mathrm{SiO}_{2}$, beyond which it increased gradually. In fact, viscosities of SPN nanoemulsions were measured in the 34-45 mPa.s range, which is attributed to the formation of enhanced $\left\{14-6-14 \mathrm{GS}+\mathrm{PHPA}+\mathrm{SiO}_{2}\right\}$ network structure. Hence, SPN aqueous fluids act as beneficial oil mobility control agents for EOR studies.

Fig. 5. Viscosity profiles as function of temperature for different aqueous formulations containing (a) 146-14 GS;(b) 14-6-14 GS + PHPA; and (c) 14-6-14 GS + PHPA + SiO2. Fig 5(d) shows the pseudoplastic character of aqueous fluids, evident from viscosity versus shear rate plots at $303 \mathrm{~K}$.

\section{Flooding experiment results}

Core-flooding experiments are necessary to determine secondary and tertiary recoveries with different formulated (aqueous) chemical slugs [60]. In this study, gemini surfactant concentration greater than CMC was chosen to account for adsorption losses. PHPA $+/ \mathrm{SiO}_{2}$ were introduced in 14-6-14 GS based injection fluids as EOR performance enhancers to achieve better oil displacement data. Cumulative oil recoveries for different fluid systems were investigated as a function of injection pore volume, as presented in Fig. 6 . During water-flooding process, $45-47 \%$ of the original oil in place (OOIP) was extracted. However, residual oil remained trapped within reservoir pore-throats owing to gravity effect, inertia and capillary forces. Once [?] $95 \%$ water cut was achieved, recovery profile flattened. Thereafter, gemini surfactant/polymer/silica slug was injected as the first stage of EOR to improve oil production efficiency. The second stage of EOR incorporated flooding with chase water to maintain pressure differential and ensure continuous displacement of forward-moving oil bank. Tertiary oil recoveries of $~ 15 \%$ was achieved during $\{14-6-14$ GS + chase water $\}$ flooding, which subsequently improved to $\sim 17 \%$ and $\sim 18 \%$ for $\{14-6-14$ GS + PHPA + chase water $\}$ and $\left\{14-6-14\right.$ GS + PHPA $+\mathrm{SiO}_{2}$ chase water $\}$ systems respectively. The secondary and tertiary flooding 
data results were employed as input data for (CMOST) assisted history-matching functions, discussed in subsequent sections $[18,19,27,37]$.

Fig. 6. Oil recovery performance of aqueous surfactant/polymer/nanoparticle solution in core-flooding systems.

\section{STARS Modelling approach for Coreflood Simulation \\ 2. Core Model Building}

The STARS (CMG) tool replicates a cylindrical sandstone core with volume of $91.952 \mathrm{~cm}^{3}$. A Cartesian system was developed with single porosity model, as shown in Fig. 7. A rectangular grid with 100 blocks (each length $0.0874 \mathrm{~cm}$ ) in I-direction, height $(3.243 \mathrm{~cm})$ and width $(3.243 \mathrm{~cm})$ was created initially such that its volume is equal to that of laboratory core. The grid pattern was mapped as centroid function along X-axis to obtain appropriate STARS model. In subsequent studies, Case scenarios I, II and III refer to core-flooding simulation models pertaining to $\{$ water-flood + surfactant EOR $\}$, \{water flood + surfactant-polymer EOR , and $\{$ water flood + surfactant-polymer-nanoparticle EOR $\}$ systems respectively.

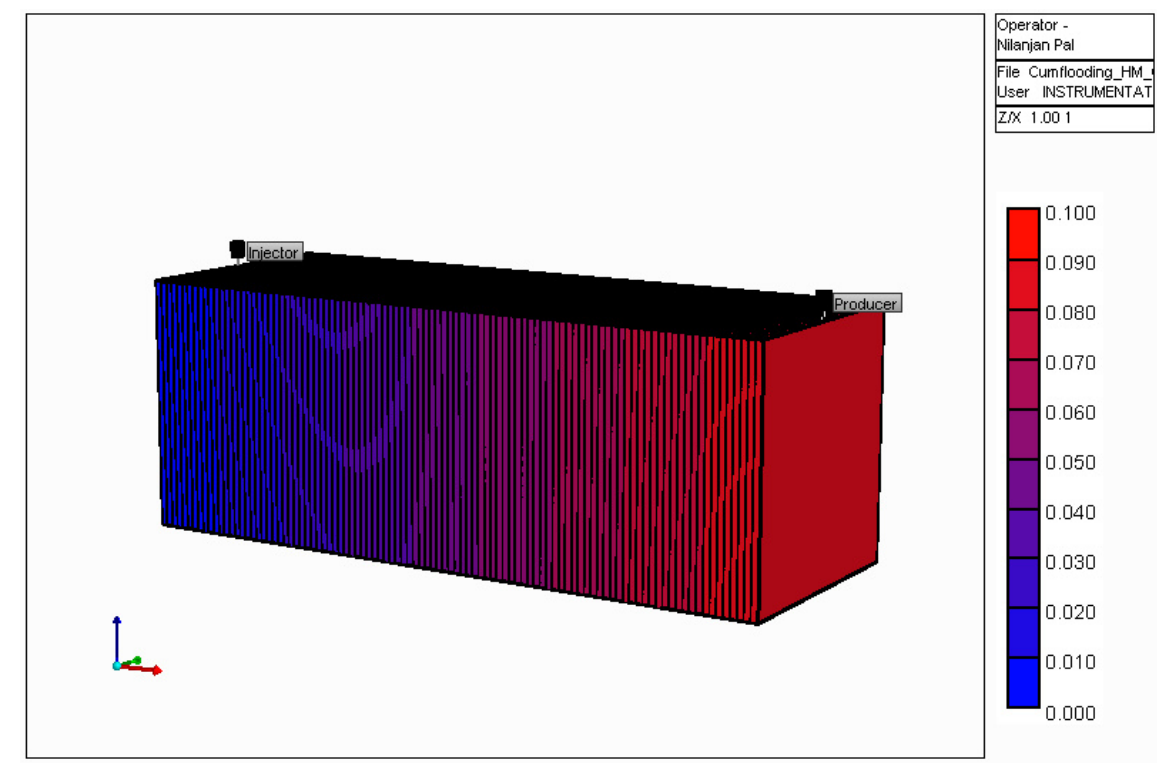

Fig. 7. Cartesian grid (centroid X) pattern for flooding simulation.

\section{Rock-Fluid Properties and Well Completion}

After building the reservoir grid model in STARS, the input/output frequency control was set and different variables relevant to our prescribed reservoir model were chosen. Fig. 8 depicts the porosity map in case of surfactant/polymer/nanoparticle flooding. Porosity in each case were measured in the range $17-18 \%$. Formation pore volume of core samples were measured during brine saturation, and observed as $16.00 \mathrm{~cm}^{3}$, $16.22 \mathrm{~cm}^{3}$ and $16.51 \mathrm{~cm}^{3}$ for I, II and III respectively. Liquid permeabilities were obtained in the range 350-400 mD, as calculated from flow-meter tests. Thereafter, liquid saturation values were incorporated in a well-sorted consolidated sandstone rock. Initial oil saturation values were inputted as $79.76 \%, 80.08 \%$ and $80.25 \%$ prior to secondary and tertiary recovery tests; for surfactant, surfactant-polymer and surfactantpolymer-nanoparticle flooding models respectively in CMG-STARS model. It was assumed that no solvent gas was present within the core before and during recovery tests. The injector well was created at the node $\left[\begin{array}{lll}1 & 1 & 1\end{array}\right]$, whereas the producer well was situated at [ $\left[\begin{array}{lll}100 & 1 & 1\end{array}\right]$. The well-bore radius was fixed at $1 \mathrm{~cm}(0.01 \mathrm{~m})$ in K-direction. Datasets related to grid formation, formation pore volume, oil phase volume, temperature, initial saturation, and temperature are shown in Table 3. 


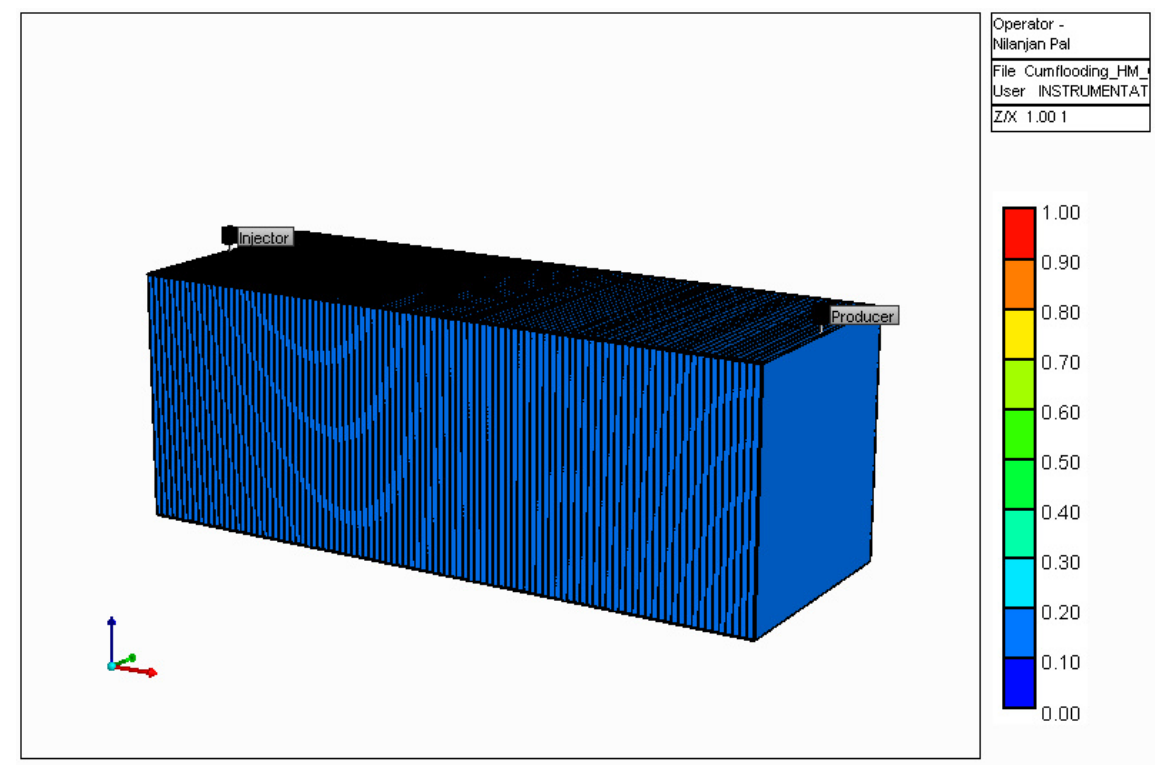

Fig. 8. Porosity map for each flooding systems. Rock porosities were measured in the range 17-18\%, showing similar profiles/contour maps.

Table 3. Summary of petrophysical data for sandstone core model using CMG-STARS

\begin{tabular}{|c|c|c|c|}
\hline Model parameters & $\{14-6-14$ GS $\}$ flood & \{14-6-14 GS + PHPA $\}$ flood & \{14-6-14 GS + PHPA + Sil \\
\hline Number of Grids & $100 \times 1 \times 1$ & $100 \times 1 \times 1$ & $100 \times 1 \times 1$ \\
\hline Sandpack length (I-axis) & $8.74 \mathrm{~cm}$ & $8.74 \mathrm{~cm}$ & $8.74 \mathrm{~cm}$ \\
\hline Grid dimensions (J, K axes) & $3.24,3.24 \mathrm{~cm}$ & $3.24,3.24 \mathrm{~cm}$ & $3.24,3.24 \mathrm{~cm}$ \\
\hline Porosity & 0.1740 & 0.1764 & 0.1796 \\
\hline Formation pore volume & $16.00 \mathrm{~cm}^{3}$ & $16.22 \mathrm{~cm}^{3}$ & $16.51 \mathrm{~cm}^{3}$ \\
\hline Permeability & $375 \mathrm{mD}$ & $381 \mathrm{mD}$ & $390 \mathrm{mD}$ \\
\hline Oil phase volume & $12.76 \mathrm{~cm}^{3}$ & $12.98 \mathrm{~cm}^{3}$ & $13.25 \mathrm{~cm}^{3}$ \\
\hline Aqueous phase volume & $3.24 \mathrm{~cm}^{3}$ & $3.24 \mathrm{~cm}^{3}$ & $3.26 \mathrm{~cm}^{3}$ \\
\hline Temperature & $303 \mathrm{~K}$ & $303 \mathrm{~K}$ & $303 \mathrm{~K}$ \\
\hline Initial oil saturation $\left(\mathrm{s}_{\mathrm{oi}}\right)$ & 0.7976 & 0.8008 & 0.8025 \\
\hline Solvent Gas present & No & No & No \\
\hline Injector well node [ $\mathrm{x}$ y z $]$ & {$\left[\begin{array}{lll}1 & 1 & 1\end{array}\right]$} & {$\left[\begin{array}{lll}1 & 1 & 1\end{array}\right]$} & {$\left[\begin{array}{lll}1 & 1 & 1\end{array}\right]$} \\
\hline Producer well node [ $\left.\begin{array}{ll}x & y \\
z\end{array}\right]$ & {$\left[\begin{array}{lll}100 & 1 & 1\end{array}\right]$} & {$\left[\begin{array}{lll}100 & 1 & 1\end{array}\right]$} & {$\left[\begin{array}{lll}100 & 1 & 1\end{array}\right]$} \\
\hline Well-bore radius (direction) & $1 \mathrm{~cm}, \mathrm{~K}$-axis & $1 \mathrm{~cm}, \mathrm{~K}$-axis & $1 \mathrm{~cm}, \mathrm{~K}$-axis \\
\hline
\end{tabular}

\section{Chemical fluid component and Injection Strategy}

After finalizing well pattern and rock-fluid parameters, injection parameters were set in the simulator. Initially, the secondary water-flood injection stage continued for a period of 0.1444 days (208 min) at a flow rate of $0.00024 \mathrm{~m}^{3} /$ day. This was followed by chemical flood injection, in which surfactant/polymer/nanoparticle based aqueous fluids were injected at the same rate to recover additional oil trapped within pore-throat regions. This process continued for 86 min duration until cumulative period of 0.2041 day. Finally, chase water was injected during 0.2041-0.3083 day period $(\sim 150 \mathrm{~min})$ to maintain pressure gradient. Earlier researchers developed simulation models using CMG-STARS and CMOST for core-scale flooding studies [61-63]. This is advantageous in understanding reservoir and fluid properties, and accurately simulate enhanced flood- 
ing performance parameters $[62,63]$. Table 4 shows the flooding model comparisons for different injection schemes employed during displacement experiments.

Table 4. Secondary and tertiary flood model comparisons and Injection schemes

\begin{tabular}{|c|c|c|c|c|}
\hline $\begin{array}{l}\text { Core-flood } \\
\text { (laboratory) } \\
\text { Parameters for } \\
\text { different EOR } \\
\text { techniques }\end{array}$ & $\begin{array}{l}\text { Core-flood } \\
\text { (laboratory) } \\
\text { Parameters for } \\
\text { different EOR } \\
\text { techniques }\end{array}$ & $\begin{array}{l}\text { Core-flood } \\
\text { (laboratory) } \\
\text { Parameters for } \\
\text { different EOR } \\
\text { techniques }\end{array}$ & $\begin{array}{l}\text { Core-flood } \\
\text { (laboratory) } \\
\text { Parameters for } \\
\text { different EOR } \\
\text { techniques }\end{array}$ & $\begin{array}{l}\text { Core-flood } \\
\text { (laboratory) } \\
\text { Parameters for } \\
\text { different EOR } \\
\text { techniques }\end{array}$ \\
\hline \multirow[t]{2}{*}{$\begin{array}{l}\text { Aqueous fluid } \\
\text { injected @ } \\
0.00024 \mathrm{~m}^{3} / \text { day } \\
\text { STW (surface } \\
\text { water rate) }\end{array}$} & $\begin{array}{l}\text { Aqueous fluid } \\
\text { injected @ } \\
0.00024 \mathrm{~m}^{3} / \text { day } \\
\text { STW (surface } \\
\text { water rate) }\end{array}$ & First Slug & Second Slug & Third Slug \\
\hline & & $0-0.1444$ day & $\begin{array}{l}0.1444-0.2041 \\
\text { day }\end{array}$ & $\begin{array}{l}0.2041-0.3083 \\
\text { day }\end{array}$ \\
\hline \multirow[t]{5}{*}{$\begin{array}{l}\text { Gemini } \\
\text { surfactant } \\
\text { flooding }\end{array}$} & $\begin{array}{l}\text { Injected Fluid } \\
\text { composition }\end{array}$ & $\begin{array}{l}1.0 \% \mathrm{NaCl} \\
\text { brine (Injected } \\
\text { Water) }\end{array}$ & Chemical fluid & $\begin{array}{l}1.0 \% \mathrm{NaCl} \\
\text { brine (Injected } \\
\text { Water) }\end{array}$ \\
\hline & $\begin{array}{l}\text { Simulation run } \\
\text { time }\end{array}$ & 208 min & $86 \min$ & 150 min \\
\hline & Time-step (min) & 2 & 2 & 2 \\
\hline & $\begin{array}{l}\text { EOR model } \\
\text { Wetting phase } \\
\text { parameter } \\
\text { (DTRAPW) }\end{array}$ & $\begin{array}{l}\text { Water-flood } \\
-5\end{array}$ & $\begin{array}{l}\text { Chemical flood } \\
-4 \text { to }-2\end{array}$ & $\begin{array}{l}\text { Chase water-flood } \\
-2.5 \text { to }-0.5\end{array}$ \\
\hline & $\begin{array}{l}\text { Number of } \\
\text { CMOST runs }\end{array}$ & 1500 & 2000 & 2000 \\
\hline \multirow{5}{*}{$\begin{array}{l}\text { \{Gemini } \\
\text { surfactant }+ \\
\text { Polymer } \\
\text { flooding }\end{array}$} & $\begin{array}{l}\text { Injected Fluid } \\
\text { composition }\end{array}$ & $\begin{array}{l}1.0 \% \mathrm{NaCl} \\
\text { brine (Injected } \\
\text { Water) }\end{array}$ & $\begin{array}{l}0.10 \% 14-6-14 \\
\text { GS }+0.05 \% \\
\text { PHPA }\end{array}$ & $\begin{array}{l}1.0 \% \mathrm{NaCl} \\
\text { brine (Injected } \\
\text { Water) }\end{array}$ \\
\hline & $\begin{array}{l}\text { Simulation run } \\
\text { time }\end{array}$ & $208 \min$ & $86 \min$ & $150 \min$ \\
\hline & Time-step (min) & 2 & 2 & 2 \\
\hline & $\begin{array}{l}\text { Process model } \\
\text { Wetting phase } \\
\text { parameter } \\
\text { (DTRAPW) }\end{array}$ & $\begin{array}{l}\text { Water-flood } \\
-5\end{array}$ & $\begin{array}{l}\text { Chemical flood } \\
-4 \text { to }-2\end{array}$ & $\begin{array}{l}\text { Chase water-flood } \\
-2.5 \text { to }-0.5\end{array}$ \\
\hline & Corey exponent & 1500 & 2000 & 2000 \\
\hline \multirow[t]{4}{*}{$\begin{array}{l}\text { \{Gemini } \\
\text { surfactant }+ \\
\text { Polymer }+ \\
\text { Nanoparticle\} } \\
\text { flooding }\end{array}$} & $\begin{array}{l}\text { Injected Fluid } \\
\text { composition }\end{array}$ & $\begin{array}{l}1.0 \% \mathrm{NaCl} \\
\text { brine (Injected } \\
\text { Water) }\end{array}$ & $\begin{array}{l}0.10 \% 14-6-14 \\
\text { GS }+0.05 \% \\
\text { PHPA }+ \\
0.025 \% \mathrm{SiO}_{2}\end{array}$ & $\begin{array}{l}1.0 \% \mathrm{NaCl} \\
\text { brine (Injected } \\
\text { Water) }\end{array}$ \\
\hline & $\begin{array}{l}\text { Simulation run } \\
\text { time }\end{array}$ & $208 \min$ & $86 \mathrm{~min}$ & $150 \mathrm{~min}$ \\
\hline & Time-step (min) & 2 & 2 & 2 \\
\hline & EOR Process & Water-flood & Chemical flood & Chase water-flood \\
\hline
\end{tabular}




\begin{tabular}{|c|c|c|c|c|}
\hline $\begin{array}{l}\text { Core-flood } \\
\text { (laboratory) } \\
\text { Parameters for } \\
\text { different EOR } \\
\text { techniques }\end{array}$ & $\begin{array}{l}\text { Core-flood } \\
\text { (laboratory) } \\
\text { Parameters for } \\
\text { different EOR } \\
\text { techniques }\end{array}$ & $\begin{array}{l}\text { Core-flood } \\
\text { (laboratory) } \\
\text { Parameters for } \\
\text { different EOR } \\
\text { techniques }\end{array}$ & $\begin{array}{l}\text { Core-flood } \\
\text { (laboratory) } \\
\text { Parameters for } \\
\text { different EOR } \\
\text { techniques }\end{array}$ & $\begin{array}{l}\text { Core-flood } \\
\text { (laboratory) } \\
\text { Parameters for } \\
\text { different EOR } \\
\text { techniques }\end{array}$ \\
\hline & $\begin{array}{l}\text { Wetting phase } \\
\text { parameter } \\
\text { (DTRAPW) }\end{array}$ & -5 & -4 to -2 & -2.5 to -0.5 \\
\hline & Corey exponent & 1500 & 2000 & 2000 \\
\hline
\end{tabular}

1. Simulation run and History-Matching with CMOST

2. Oil saturation images/maps at different stages of simulation

Core-scale simulation runs were conducted to investigate the potential of secondary and tertiary recovery processes in qualitative aspects. Based on history matching of experimental data conducted during different flooding techniques, maps showing oil saturation $\left(\mathrm{s}_{\mathrm{oi}}\right)$ were generated at different time intervals, as presented in Figs. 9(a), 9(b) and 9(c). As mentioned earlier, case scenarios I, II and III refer to flooding studies in the presence of $\{0.10 \% 14-6-14$ GS $\},\{0.10 \% 14-6-14$ GS $+0.05 \%$ PHPA $\}$ and $\{0.10 \% 14-6-14$ GS $+0.05 \%$ PHPA $\left.+0.025 \% \mathrm{SiO}_{2}\right\}$ respectively. At initial time $(\mathrm{t}=0)$, the porous rock model was saturated with crude oil. At this stage, initial oil saturation $\left(\mathrm{s}_{\mathrm{oi}}\right)$ percentages were measured as $79.76 \%$ for case I, $80.08 \%$ for case II, and $80.25 \%$ for case III. This represents the original oil in place (OOIP). In each case scenario, same brine solution containing $1.0 \% \mathrm{NaCl}$ was injected at constant flow rate $\left(0.00024 \mathrm{~m}^{3} /\right.$ day or $\left.10 \mathrm{ml} / \mathrm{h}\right)$ as a form of secondary recovery process. During this process, the oil saturation within porous model gradually decreased over time $[17,27,64]$. This is evident from the evolution of Cartesian grid images from brown/red (previously) to a yellow/green hue, which is indicative of decreasing oil saturation. For case I, oil saturation values decreased from $79.76 \%$ (initial time) to $59.12 \%, 53.44 \%$ and $43.97 \%$ at the end of $30 \mathrm{~min}, 60 \mathrm{~min}$ and 208 min respectively. Similarly, respective oil saturation percentages after 30, 60 and 208 min were observed to be $59.78 \%, 54.13 \%$ and $44.69 \%$ for case II; and $59.79 \%, 54.07 \%$ and $44.35 \%$ for case III. Time-dependent data at 208 min represents the end of secondary (water-flood) recovery. It is pertinent to note that waterflooding exhibited oil saturation levels in the $43-45 \%$ range, thereby resulting in similar saturation profiles. However, main findings of the study lie in the evaluation of enhanced oil recovery results, during which \{aqueous chemical fluid + chase water $\}$ were injected successively $[18,64,65]$. Aqueous chemical flooding was introduced at the onset of 208 and was stopped at $294 \mathrm{~min}$. During the $86 \mathrm{~min}$ time-period of the first stage of EOR, oil saturation percentages were found as $36.93 \%, 35.62 \%$ and $35.06 \%$ for cases I, II and III respectively. This was followed by chase water (with $1.0 \% \mathrm{NaCl}$ ) injection until a cumulative time-period of nearly $\sim 7 \mathrm{~h} 22 \mathrm{~min}$, wherein the residual oil saturation $\left(\mathrm{s}_{\mathrm{or}}\right)$ was investigated. The $\mathrm{s}_{\mathrm{or}}$ values corresponding to I, II, and III were determined from history-match results as $31.96 \%, 30.68 \%$ and $29.30 \%$ respectively. In summary, analyses of oil saturation profiles prove that analyzed chemical fluids improve the sweep efficiency by moving the oil far away from the injector well, and extract oil from producer well. 
(a)

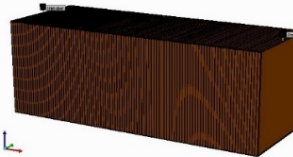

Initial : 0 min

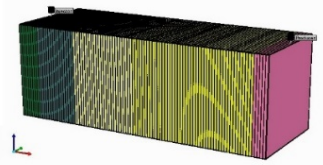

After Water-Flood : $208 \mathrm{~min}$
L

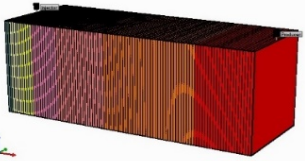

During Water-Flood : $30 \mathrm{~min}$

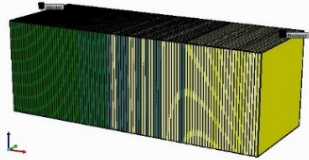

After GS Flood : $294 \mathrm{~min}$

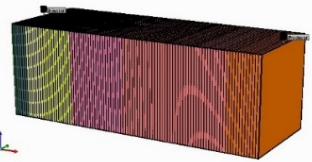

During Water-Flood : $60 \mathrm{~min}$

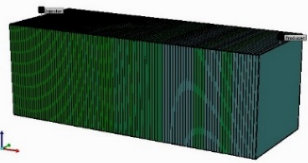

After Chase water Flood : $444 \mathrm{~min}$

0.000 .050 .100 .150 .200 .250 .300 .350 .400 .450 .500 .550 .600 .650 .700 .750 .800 .850 .900 .951 .00

(b)

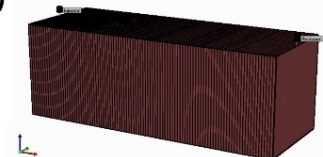

Initial : 0 min

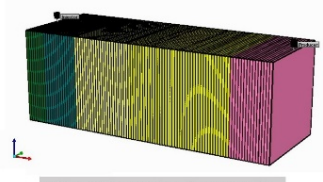

After Water-Flood : $208 \mathrm{~min}$

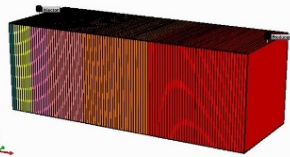

During Water-Flood : $\mathbf{3 0}$ min

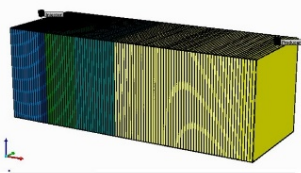

After $\{$ GS + PHPA $\}$ Flood : $294 \mathrm{~min}$

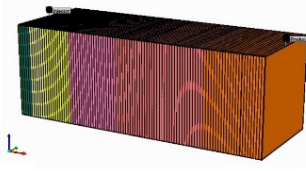

During Water-Flood : $60 \mathrm{~min}$

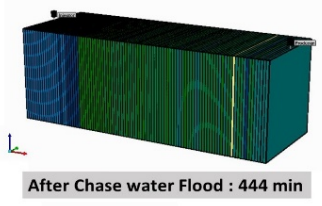

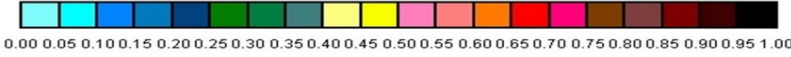

(c)

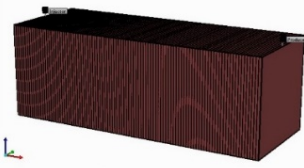

Initial : 0 min

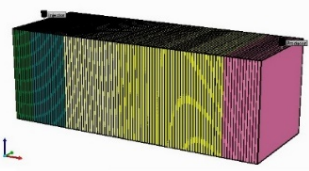

After Water-Flood : $208 \mathrm{~min}$

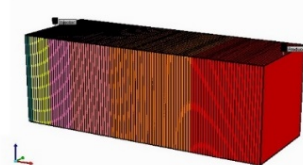

During Water-Flood : 30 min

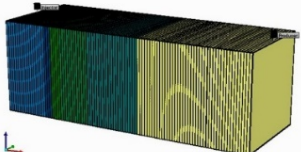

After $\left\{\right.$ GS + PHPA + SiO $\left._{2}\right\}$ Flood : $294 \mathrm{~min}$
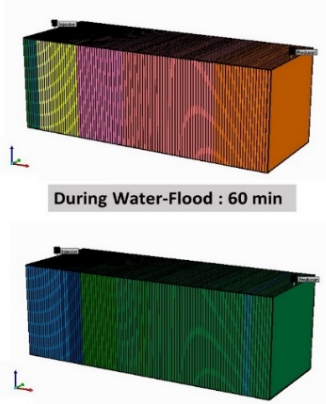

After Chase water Flood : $444 \mathrm{~min}$

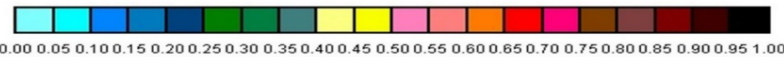

Fig. 9. Oil saturation profiles for different stages of flooding at the end of 0, 30, 60, 208, 294, 444 min in case of:(a) 14-6-14 GS; (b) 14-6-14 GS + PHPA; and(c) 14-6-14 GS + PHPA + $\mathrm{SiO}_{2}$.

Relative permeability curve analysis

In the presence of multiple fluid systems such as oil and water, relative permeability describes the alteration in flow behavior with saturation change. This is commonly observed during secondary and tertiary flood- 
ing studies involving chemical induced displacement of oil/water in porous media applications. Wettability alteration, pore morphology, fluid distribution and saturation data are primary parameters that influence relative permeability measurements $[66,67]$. Figs. 10(a), 10(b) and 10(c) show the water/oil relative permeability plots obtained during different flooding simulations. Solid lines represent experimental data curves, wherein adjusted curves obtained after CMOST assisted history matching are represented with help of dotted lines. Initially, the core reservoir is in intermediate-wet state, in which rock pore surfaces are wetted with oil and water exists within the central regions between the pores. It is evident that relative permeabilities for oil and water phases vary significantly with increasing water saturation, which is brought about during brine/chemical injection [67]. In summary, simulation studies prove that the wetting nature of rock is altered to strongly water-wet state.

Fig. 10. Relative permeability curves of different case scenarios involving: (a) 14-6-14 GS; (b) 14-6-14 GS + PHPA; and (c) 14-6-14 GS + PHPA + $\mathrm{SiO}_{2}$ flooding.

\section{Cumulative oil production during secondary and tertiary flooding}

The oil recovery performance of surfactant, surfactant-polymer and surfactant-polymer-nanoparticle based aqueous chemical fluids were corroborated by history matching of experimental data. In previous section, the laboratory results of flooding studies were discussed for different chemical formulations (see Fig. 6). However, it is important to study the validity of these results with compositional fluid flow simulations such as CMG $[17,18]$. Fig. 11 shows a good match between experimental and simulated outcomes of different flooding scenarios. Experimental analyses revealed that water-flooding processes extracted respective volumes of 5.73 $\mathrm{cm}^{3}, 5.74 \mathrm{~cm}^{3}$ and $5.93 \mathrm{~cm}^{3}$ of initial oil content in case scenarios I, II and II respectively. Simulation studies showed water-flood recoveries of $44.86 \%, 44.31 \%$ and $44.99 \%$ respectively at the end of secondary recovery, which is in close agreement with experimental results. Simulation studies on tertiary flooding studies showed crude oil recoveries of $7.65 \mathrm{~cm}^{3}, 8.01 \mathrm{~cm}^{3}$ and $8.41 \mathrm{~cm}^{3}$ in the presence of $\{14-6-14 \mathrm{GS}+$ chase water $\},\{14-$ 6-14 GS + PHPA + chase water $\}$ and $\left\{14-6-14 \mathrm{GS}+\mathrm{PHPA}+\mathrm{SiO}_{2}\right.$ chase water $\}$ respectively.

Fig. 11. Cumulative oil production versus time plots for:(a) 14-6-14 GS; (b) 14-6-14 GS + PHPA; (c)146-14 GS + PHPA + $\mathrm{SiO}_{2}$ showing match between experimental and CMG-STARS results.

The error between experimental and simulated results for cumulative flooding studies was obtained with the help of CMG-DECE (Designed Exploration Controlled. Evolution) engine with 2000 experiments. Figs. 12(a), 12(b) and 12(c) presents the global history match (HM) error versus experiment ID plots for cases I, II and III respectively. It is evident that the simulation models were tailored during history match to achieve optimized result(s) in the search direction of minimal error. Error percentages with values [?] $6.00 \%$ between the history matched and experimental models was achieved during the simulation run. Cases I, II and III registered the most optimal results for experiment ID nos. 1791 (within $\pm 5.85 \%$ error), 1017 ( $\pm 4.38 \%$ error) and 1753 ( $\pm 5.23 \%$ error) respectively. This optimized model was validated to match imput fluid and rock conditions, and used as the best-fitted model to explain flooding performances of different fluid systems. Table 5 shows the rock-fluid parameters and flooding results for different case scenarios. The parametric results were obtained from careful analysis of histogram plots over significant number of simulation runs. The recovery rates, oil/water permeability curves, rock-wetting properties and fluid flow parameters were tuned during the history matching process. The study ultimately presents the success of surfactant flood, surfactant-polymer flood and surfactant-polymer-nanoparticle flood models in simulating the experimental outcomes, and confirms their relative efficiencies [17,18,26,27,35].

Fig. 12. History matching error between experimental and simulated models, showing the base case, general solutions and optimal solution for cumulative flooding characterized by : (a) 14-6-14 GS; (b) 14-6-14 GS + PHPA; (c) 14-6-14 GS + PHPA + $\mathrm{SiO}_{2}$

Table 5. Petrophysical properties and Flooding Simulation Results from history matching 


\begin{tabular}{|c|c|c|c|c|}
\hline $\begin{array}{l}\text { Flooding } \\
\text { performance }\end{array}$ & $\begin{array}{l}\text { Flooding } \\
\text { performance }\end{array}$ & Surfactant flood & $\begin{array}{l}\text { Surfactant- } \\
\text { Polymer (SP) } \\
\text { Flood }\end{array}$ & $\begin{array}{l}\text { Surfactant- } \\
\text { Polymer- } \\
\text { Nanoparticle } \\
\text { flood }\end{array}$ \\
\hline $\begin{array}{l}\text { Injection Fluid } \\
\text { composition }\end{array}$ & $\begin{array}{l}\text { Injection Fluid } \\
\text { composition }\end{array}$ & $\begin{array}{l}\text { Brine }+\{0.10 \% \\
14-6-14 \text { GS }+ \\
\text { Chase water }\}\end{array}$ & $\begin{array}{l}\text { Brine }+\{0.10 \% \\
14-6-14 \text { GS }+ \\
0.05 \% \text { PHPA }+ \\
\text { Chase water }\}\end{array}$ & $\begin{array}{l}\text { Brine }+\{0.10 \% \\
14-6-14 \mathrm{GS}+ \\
0.05 \% \mathrm{PHPA}^{+} \\
0.025 \% \mathrm{SiO}_{2}+ \\
\text { Chase water }\}\end{array}$ \\
\hline $\begin{array}{l}\text { Pore volume } \\
(\mathrm{PV})\end{array}$ & $\begin{array}{l}\text { Pore volume } \\
(\mathrm{PV})\end{array}$ & $16.00 \mathrm{~cm}^{3}$ & $16.22 \mathrm{~cm}^{3}$ & $16.51 \mathrm{~cm}^{3}$ \\
\hline $\begin{array}{l}\text { Initial Oil } \\
\text { Volume }\end{array}$ & $\begin{array}{l}\text { Initial Oil } \\
\text { Volume }\end{array}$ & $12.76 \mathrm{~cm}^{3}$ & $12.99 \mathrm{~cm}^{3}$ & $13.25 \mathrm{~cm}^{3}$ \\
\hline $\begin{array}{l}\text { Initial oil } \\
\text { saturation }\left(S_{o i}\right)\end{array}$ & $\begin{array}{l}\text { Initial oil } \\
\text { saturation }\left(\mathrm{S}_{\mathrm{oi}}\right)\end{array}$ & 0.7976 & 0.8008 & 0.8025 \\
\hline $\begin{array}{l}\text { Residual oil } \\
\text { saturation } \\
\text { (Sor) }\end{array}$ & $\begin{array}{l}\text { Residual oil } \\
\text { saturation } \\
\text { (Sor) }\end{array}$ & 0.3196 & 0.3068 & 0.2930 \\
\hline \multirow{2}{*}{$\begin{array}{l}\text { Secondary } \\
\text { recovery (\% } \\
\text { OOIP) }\end{array}$} & Experimental & 46.33 & 45.46 & 45.91 \\
\hline & $\begin{array}{l}\text { Simulation } \\
\text { Global HM } \\
\text { Error (\%) }\end{array}$ & $\begin{array}{l}44.86 \\
\pm 8.83\end{array}$ & $\begin{array}{l}44.27 \\
\pm 11.03\end{array}$ & $\begin{array}{l}44.99 \\
\pm 10.21\end{array}$ \\
\hline \multirow{2}{*}{$\begin{array}{l}\text { Tertiary recovery } \\
(\% \text { OOIP })\end{array}$} & Experimental & 15.29 & 17.40 & 18.15 \\
\hline & $\begin{array}{l}\text { Simulation } \\
\text { Global HM } \\
\text { Error (\%) }\end{array}$ & $\begin{array}{l}15.06 \\
\pm 5.85\end{array}$ & $\begin{array}{l}17.42 \\
\pm 4.38\end{array}$ & $\begin{array}{l}18.49 \\
\pm 5.23\end{array}$ \\
\hline $\begin{array}{l}\text { Cumulative } \\
\text { recovery (\% } \\
\text { OOIP) }\end{array}$ & $\begin{array}{l}\text { Cumulative } \\
\text { recovery (\% } \\
\text { OOIP) }\end{array}$ & 59.92 & 61.69 & 63.48 \\
\hline
\end{tabular}

\section{Flooding Performance analysis and Decision Criteria}

CMG-STARS is useful in modelling the surfactant/polymer/nanoparticle flooding experiment, with good agreement between the experimental and simulated data [17,37,65,68]. Figs. 13(a), 13(b) and 13(c) show the oil saturation, water cut and recovery factor profiles for different chemical fluid compositions respectively. A Cartesian model was developed with constant injection rate and constant pressure condition to investigate the EOR performance of analyzed fluids. Oil saturation curves showed that surfactant-polymer-nanoparticle aqueous fluids are capable of extracting maximum amount of trapped crude oil in comparison to other analyzed systems. The residual oil saturation ( $\mathrm{s}_{\text {or }}$ ) values for cases I, II and III were found to be $31.96 \%$, $30.68 \%$ and $29.30 \%$ respectively at the end of simulation tests. Crude oil was recovered during secondary flooding experiments, until water cut reaches [?] 95\%. At this stage, tertiary fluids were introduced to improve oil production and reduce water cut percentages. All three flooding instances discussed herein showed similar behavior in terms of water cut versus pore volume plots. In fact, oil displacement experiment was stopped when the quantity of produced oil was extremely low from economical aspect. EOR investigations achieved crude oil recoveries of $15.06 \%$ during $\{14-6-14$ GS + chase water $\}$ flooding, $17.42 \%$ during $\{14-6-14$ GS + PHPA + chase water $\}$ flooding, and $18.49 \%$ during $\left\{14-6-14\right.$ GS + PHPA $+\mathrm{SiO}_{2}+$ chase water $\}$ flooding. Surfactant-polymer-nanoparticle (SPN) flooding recovered an additional $\sim 1.07 \%$ of OOIP over surfactant-polymer flooding; and $3.43 \%$ over conventional surfactant flooding process. The simulated results 
were successfully matched with experimental flooding data. This may not seem very significant in terms of percentages. However, if the field-scale data is assumed, additional barrels of crude oil can be produced. This translates to improved efficacy of surfactant-polymer-nanoparticle based EOR method.

Fig. 13. Flooding performance versus injected pore volume (PV) of different aqueous EOR fluids, expressed in terms of (a) oil saturation; (b) water cut; and (c) recovery factor.

\section{Conclusions}

Laboratory core-flood experiments were simulated using CMG-STARS to investigate the flooding performance of \{14-6-14 GS + / PHPA polymer + / $\mathrm{SiO}_{2}$ nanoparticle $\}$ aqueous fluids. Aqueous chemical systems exhibited ultra-low IFT, rock-wetting behavior and pseudoplastic flow character, as evident from experimental analyses. Surfactant fluids were characterized by micelles/aggregates in bulk phase, which altered to network structure of dispersed micelles interconnected by entangled polymer chains in surfactant-polymer solutions. This structural attribute becomes more pronounced in the surfactant-polymer-nanoparticle (SPN) fluids, resulting in the formation of supra-molecular network structure with enhanced oil-attracting properties. Cartesian single-porosity model was employed to develop a robust numerical approach to match flooding properties of analyzed fluids. Initially, water-flood was simulated for $208 \mathrm{~min}$. After secondary oil recovery, tertiary chemicals were injected to improve oil production and maintain pressure drop within reservoir pore-throats. This flooding process involved chemical injection period of $86 \mathrm{~min}$, and $150 \mathrm{~min}$ chase-water flooding period. Oil saturation maps showed that oil saturation within core sample decreased to $31.96 \%, 30.68 \%$ and $29.30 \%$ of original liquid content at the end of flooding studies, involving \{14-6-14 GS $\},\{14-6-14$ GS + PHPA $\}$ and $\left\{14-6-14\right.$ GS + PHPA $\left.+\mathrm{SiO}_{2}\right\}$ fluids respectively. Relative permeability curves were adjusted to model flooding results, and proved to be useful in predicting oil displacement results. Tertiary flooding simulations revealed EOR percentages of $15.06 \%, 17.42 \%$ and $18.49 \%$ of original oil in place (OOIP) in the presence of \{14-6-14 GS + chase water $\},\{14-6-14$ GS + PHPA + chase water $\}$ and $\{14-6-14$ $\mathrm{GS}+\mathrm{PHPA}+\mathrm{SiO}_{2}+$ chase water $\}$ respectively. In summary, the analyzed aqueous fluids exhibit favorable recoveries and economic feasibility for EOR in sandstone rock systems.

\section{Acknowledgements}

The authors are grateful to the Department of Petroleum Engineering, Indian Institute of Technology Dhanbad, India for providing (educational) licensed version of CMG General Release to perform reservoir simulation studies.

\section{Conflict of Interest}

The authors declare no competing financial interest(s).

\section{References}

1. Wen, X.; Wei, Y.; Huang, D. Measuring contagion between energy market and stock market during financial crisis: A copula approach, Energy Econ. 2012, 34, 1435-1446. https://doi.org/10.1016/j.eneco.2012.06.021.

2. Lang, K.; Auer, B.R. The economic and financial properties of crude oil: A review, The North Am. J. Econ. Finance 2020, 52, 100914. https://doi.org/10.1016/j.najef.2019.01.011.

3. Negin, C.; Ali, S.; Xie, Q. Most common surfactants employed in chemical enhanced oil recovery. Petroleum 2017,3, 197-211. https://doi.org/10.1016/j.petlm.2016.11.007.

4. Satter, A.; Iqbal, G.M. Enhanced oil recovery processes: thermal, chemical, and miscible floods, in: Satter, A., Iqbal, G.M. (Eds.), Reservoir Engineering. Gulf Professional Publishing, 2016, pp 313-337. https://doi.org/10.1016/B978-0-12-800219-3.00017-6.

5. Cayias J.L., Schechter R.S.; Wade W.H. Modeling crude oils for low interfacial tension. Soc. Pet. Eng. J. 1976, 16, 351-357. https://doi.org/10.2118/5813-PA.

6. Kamal, M.S. A Review of Gemini Surfactants: Potential Application in Enhanced Oil Recovery. J. Surfactants Deterg. 2016, 19(2), 223-236. DOI: 10.1007/s11743-015-1776-5. 
7. Zhang, S.; Jiang, G.-C.; Wang, L.; Guo, H.-T.; Tang, X.-G.; Bai, D.-G. Foam Flooding with Ultra-Low Interfacial Tension to Enhance Heavy Oil Recovery. J. Dispersion Sci. Technol. 2014, 35(3), 403-410. doi:10.1080/01932691.2013.792272.

8. Qi, P.; Ehrenfried, D.H.; Koh, H.; Balhoff, M.T. Reduction of Residual Oil Saturation in Sandstone Cores by Use of Viscoelastic Polymers. Soc. Pet. Eng. J. 2017, SPE-179689-MS, 1-15. doi:10.2118/179689-PA

9. Farajzadeh, R.; Wassing, B.L.; Lake, L.W. Insights into design of mobility control for chemical enhanced oil recovery. Energy Rep. 2019, 5, 570-578. https://doi.org/10.1016/j.egyr.2019.05.001.

10. Zhang, H.; Ramakrishnan, T.S.; Nikolov, A.; Wasan, D. Methods and systems for enhanced oil recovery employing nanofluids. Pat. US20190024487A1, United States, 2017.

11. Rognmo, A.U.; Al-Khayyat, N.; Heldal, S.; Vikingstad, I.; Eide, Ø.; Fredriksen, S.B.; Alcorn, Z.P.; Fraue, A.; Bryant, S.L.; Kovscek, A.R.; Fern $\varnothing$, M. A. Performance of Silica Nanoparticles in CO2 Foam for EOR and CCUS at Tough Reservoir Conditions. Soc. Pet. Eng. 2020, SPE-191318-MS, 1-12. doi:10.2118/191318-PA.

12. Kamari, A.; Nikookar, M.; Sahranavard, L.; Mohammadi, A.H. Efficient screening of enhanced oil recovery methods and predictive economic analysis. Neural Comput. Appl. 2014, 25, 815-824. https://doi.org/10.1007/s00521-014-1553-9.

13. Zuloaga-Molero, P.; Yu, W.; Xu, Y.; Sepehrnoori, K.; Li, B. Simulation Study of $\mathrm{CO}_{2}$-EOR in Tight Oil Reservoirs with Complex Fracture Geometries. Sci. Rep. 2016, 6, 33445. https://doi.org/10.1038/srep33445.

14. Su, S.; Giddins, M.A.; Kuznetsov, D.; Naccache, P.; Clarke, A.; Fordham, E.J.; Hawkes, L.; Howe, A.; Mitchell, J.; Staniland, J. Enhanced Oil Recovery (EOR) Chemical Coreflood Simulation Study Workflow. Pat. US20180032356A1, United States, 2016.

15. Guo, Z.; Dong, M.; Chen, Z.; Yao, J. Dominant Scaling Groups of Polymer Flooding for Enhanced Heavy Oil Recovery. Ind. Eng. Chem. Res. 2013, 52 (2), 911-921. DOI: 10.1021/ie300328y

16. Waggoner, J.R.; Castillo, J.L.; Lake, L.W. Simulation of EOR Processes in Stochastically Generated Permeable Media. Soc. Pet. Eng. 1992, 7, 1-8. doi:10.2118/21237-PA.

17. Goudarzi, A.; Delshad, M.; Sepehrnoori, K. A chemical EOR benchmark study of different reservoir simulators. Comput. Geosci. 2016, 94, 96-109. DOI: 10.1016/j.cageo.2016.06.013.

18. Kazempour, M.; Alvarado, V.; Manrique, E.J.; Izadi, M. Impact of Alkaline-Surfactant-Polymer Flooding Model on Upscaled Recovery Predictions: Medium and Heavy Oils. Soc. Pet. Eng. 2014, SPE171055-MS, 1-20. doi:10.2118/171055-MS.

19. Goudarzi, A.; Delshad, M.; Sepehrnoori, K. A Critical Assessment of Several Reservoir Simulators for Modeling Chemical Enhanced Oil Recovery Processes. Soc. Pet. Eng. 2013, SPE-163578-MS, 1-16. doi:10.2118/163578-MS.

20. Satoh, T. Treatment of Phase Behavior and Associated Properties Used in Micellar-Polymer Flood Simulator. The University of Texas at Austin, Austin, Texas, 1984.

21. Korrani, A.K.N.; Sepehrnoori, K.; Delshad, M. Coupling IPhreeqc with UTCHEM to model reactive flow and transport. Comput. Geosci. 2015, 82, 152-169. https://doi.org/10.1016/j.cageo.2015.06.004.

22. Morel, D.; Vert, M.; Jouenne, S.; Nahas, E. Polymer injection in deep offshore field: the Dalia Angola case. In: Proceedings of Paper SPE 116672, Presented at the Annual Technical Conference and Exhibition. 21-24 September, 2008, Denver, Colorado.

23. Lashgari, H.R.; Sepehrnoori, K.; Delshad, M.; 2016. A four-phase chemical/gas model in an implicit-pressure/explicit-concentration reservoir simulator. Soc. Pet. Eng. J., 2016, 21, 1-20. https://doi.org/10.2118/173250-PA.

24. CMG-STARS Technical Manual, 2014.

25. Lashgari, H.R.; Sepehrnoori, K.; Delshad, M. Modeling of low-tension surfactant-gas flooding process in a four-phase flow simulator. In: Proceedings of Paper SPE 175134, Presented at the SPE Annual Technical Conference and Exhibition. 28-30 September, 2015, Houston, Texas.

26. Pandey, A.; Beliveau, D.; Corbishley, D.W.; Kumar, M.S. Design of an ASP pilot for the Mangala field: laboratory evaluations and simulation studies. In: Proceedings of Paper SPE 113131, Presented at the 
Indian Oil and Gas Technical Conference and Exhibition. 4-6 March, 2008, Mumbai, India.

27. Tunnish, A.; Shirif, E.; Henni, A. History matching of experimental and CMG-STARS results. J. Petrol. Explor. Prod. Technol. 2019, 9, 341-351. https://doi.org/10.1007/s13202-018-0455-2.

28. Dahbag, M.S.B.; Hossain, M.E.; AlQuraishi, A.A. Efficiency of Ionic Liquids as an Enhanced Oil Recovery Chemical: Simulation Approach. Energy Fuels 2016, 30, 9260-9265. DOI: 10.1021/acs.energyfuels.6b01712.

29. Pal, N.; Saxena, N.; Mandal, A. Synthesis, characterization, and physicochemical properties of a series of quaternary gemini surfactants with different spacer lengths. Colloid Polym. Sci. 2017, 295, 2261-277. https://doi.org/10.1007/s00396-017-4199-1.

30. Pal, N.; Saxena, N.; Mandal, A. Equilibrium and dynamic adsorption of gemini surfactants with different spacer lengths at oil/aqueous interfaces. Colloids Surf., A 2017, 533, 20-32. https://doi.org/10.1016/j.colsurfa.2017.08.020.

31. Keshtkar, S.; Sabeti, M.; Mohammadi, A.H. Numerical approach for enhanced oil recovery with surfactant flooding. Petroleum 2016, 2, 98-107. https://doi.org/10.1016/j.petlm.2015.11.002.

32. Stanislaus, B.R.; Mahmud, H.K.B. Numerical Approach for Enhanced Oil Recovery with Surfactant Flooding using STARS (CMG). Int. J. Petrol. Petrochem. Eng. 2017, 3, 1-18. DOI: http://dx.doi.org/10.20431/2454-7980.0304001.

33. Bidner, M.S.; Savioli, G.B. On the numerical modeling for surfactant flooding of oil reservoirs. Mecanica Computacional, 2002, XXI, 566-585.

34. Dai-yin, Y.; Hui, P.U. Numerical simulation study on surfactant flooding for low permeability oilfield in the condition of threshold pressure. J. Hydrodyn., Ser. B 2008, 20, 492-498. https://doi.org/10.1016/S1001-6058(08)60085-2.

35. Druetta, P.; Yue, J.; Tesi, P.; De Persis, C.; Picchioni, F. Numerical modeling of a compositional flow for chemical EOR and its stability analysis. Appl. Math. Modell. 2017, 47, 141-159. https://doi.org/10.1016/j.apm.2017.03.017.

36. Janssen, M.T.G.; Mendez, F.A.T.; Zitha, P.L.J. Mechanistic Modeling of Water-Alternating-Gas Injection and Foam-Assisted Chemical Flooding for Enhanced Oil Recovery. Ind. Eng. Chem. Res. 2020, 59 (8), 3606-3616. DOI: 10.1021/acs.iecr.9b06356.

37. Hashmet, M.R.; AlSumaiti, A.M.; Qaiser, Y.; AlAmeri, W.S. Laboratory Investigation and Simulation Modeling of Polymer Flooding in High-Temperature, High-Salinity Carbonate Reservoirs. Energy Fuels 2017, 31, 13454-13465. DOI: 10.1021/acs.energyfuels.7b02704.

38. Qiao, C.; Khorsandi, S.; Johns, R.T. A general purpose reservoir simulation framework for multiphase multicomponent reactive fluids. Soc. Pet. Eng. 2017, SPE-182715-MS, 1-18. https://doi.org/10.2118/182715-MS.

39. Liu, H.; Chen, Z. 2018. A Scalable Thermal Reservoir Simulator for Giant Models on Parallel Computers. Comput. Eng. Finance Sci. 2018, 1-104.

40. Bakyani, A.E.; Taghizadeh, A.; Sarvestani, A.N.; Esmaeilzadeh, F.; Mowla, D. Three-dimensional and two-phase numerical simulation of fractured dry gas reservoirs. J. Petrol. Explor. Prod. Technol. 2018, 8, 1425-1441. https://doi.org/10.1007/s13202-017-0423-2.

41. Abbas, L.A.H.; Sulaiman, W.R.W.; Jaafar, M.Z.; Gbadamosi, A.O.; Ebrahimi, S.S.; Elrufai, A. Numerical study for continuous surfactant flooding considering adsorption in heterogeneous reservoir. J. King Saud Univ. Eng. Sci. 2020, 32, 91-99. https://doi.org/10.1016/j.jksues.2018.06.001.

42. Hosseini-Nasab, S.M.; Padalkar, C.; Battistutta, E.; Zitha, P.L.J. Mechanistic Modeling of the Alkaline/Surfactant/Polymer Flooding Process under Sub-optimum Salinity Conditions for Enhanced Oil Recovery. Ind. Eng. Chem. Res. 2016, 55 (24), 6875-6888. DOI: 10.1021/acs.iecr.6b01094.

43. Dahbag, M.S.B.; Al-Gawfi, A.; Hassanzadeh, H. Suitability of hot urea solutions for wettability alteration of bitumen reservoirs - Simulation of laboratory flooding experiments. Fuel 2020, 272, 117713. https://doi.org/10.1016/j.fuel.2020.117713.

44. Lashgari, H.R.; Pope, G.A.; Tagavifar, M.; Luo, H.; Sepehrnoori, K.; Li, Z.; Delshad, M. A new relative permeability model for chemical flooding simulators. J. Pet. Sci. Eng. 2018, 171, 1466-1474. https://doi.org/10.1016/j.petrol.2018.08.007. 
45. Cheng, X.; Kleppe, J.; Torsæter, O. Simulation study of surfactant injection in a fractured core. J. Pet. Explor. Prod. Technol. 2019, 9, 3079-3090. https://doi.org/10.1007/s13202-019-0705-y.

46. Hakiki, F., Maharsi, D.A., Marhaendrajana, T. Surfactant-polymer coreflood simulation and uncertainty analysis derived from laboratory study. J. Eng. Technol. Sci. 2015, 47, 706-725. https://doi.org/10.5614/j.eng.technol.sci.2015.47.6.9

47. Pal, N.; Saxena, N.; Mandal, A. Studies on the physicochemical properties of synthesized tailormade gemini surfactants for application in enhanced oil recovery. J. Mol. Liq. 2018, 258, 211-224. https://doi.org/10.1016/j.molliq.2018.03.037.

48. Stern, H.O. Zur theorie der elektrolytischen doppelschicht. Zeitschrift für Elektrochemie und angewandte physikalische Chemie 1924, 30 (21-22), 508-516. DOI: 10.1002/bbpc.192400182

49. Li, N.; Zhang, G.; Ge, J.; Luchao, J.; Jianqiang, Z.; Baodong, D.; Pei, H. Adsorption Behavior of Betaine-Type Surfactant on Quartz Sand. Energy Fuels 2011, 25, 4430-4437. DOI: 10.1021/ef200616b.

50. Nandwani, S.K.; Chakraborty, M.; Gupta, S. Adsorption of Surface Active Ionic Liquids on Different Rock Types under High Salinity Conditions. Sci. Rep. 2019, 9, 14760. DOI: 10.1038/s41598-01951318-2.

51. Bai, L.; Li, C.; Korte, C.; Huibers, B.M.J.; Pales, A.R.; Liang, W.; Ladner, D.; Daigle, H.; Darnault, C.J.G. Effects of silica-based nanostructures with raspberry-like morphology and surfactant on the interfacial behavior of light, medium, and heavy crude oils at oil-aqueous interfaces. Appl. Nanosci. 2017, 7, 947-972. DOI: 10.1007/s13204-017-0630-7

52. Gao, B.; Sharma, M.M. A family of alkyl sulfate gemini surfactants. 2. Water-oil interfacial tension reduction. J. Colloid Interface Sci. 2013, 407, 375-381. https://doi.org/10.1016/j.jcis.2013.06.066.

53. Betancur, S.; Giraldo, L.J.; Carrasco-Marin, F.; Riazi, M.; Manrique, E.J.; Quintero, H.; Garcia, H.A.; Franco-Ariza, C.A.; Cortes, F.B. Importance of the Nanofluid Preparation for Ultra-Low Interfacial Tension in Enhanced Oil Recovery Based on Surfactant-Nanoparticle-Brine System Interaction. ACS Omega 2019, 4 (14), 16171-16180. DOI: 10.1021/acsomega.9b02372.

54. Zhu, P.; Zhu, Y.; Xu, Z.C.; Zhang, L.; Zhang, L.; Zhao, S. Effect of Polymer on Dynamic Interfacial Tensions of Anionic-nonionic Surfactant Solutions, J. Dispersion Sci. Technol. 2016, 37, 820-829. DOI: 10.1080/01932691.2015.1065502.

55. SiTu, W.X.; Lu, H.M.; Ruan, C.Y.; Zhang, L.; Zhu, Y.; Zhang, L.Effect of polymer on dynamic interfacial tensions of sulfobetaine solutions. Colloids Surf., A 2017, 533, 231-240. https://doi.org/10.1016/j.colsurfa.2017.09.006.

56. Ali, J.A.; Kolo, K.; Manshad, A.K.; Mohammadi, A.H. Recent advances in application of nanotechnology in chemical enhanced oil recovery: Effects of nanoparticles on wettability alteration, interfacial tension reduction, and flooding. Egypt. J. Pet. 2008, 27, 1371-1383. https://doi.org/10.1016/j.ejpe.2018.09.006.

57. Ahmed, A.; Saaid, I.M.; Ahmed, A.A.; Pilus, R.M.; Baig, M.K. Evaluating the potential of surfacemodified silica nanoparticles using internal olefin sulfonate for enhanced oil recovery. Pet. Sci. 2019. https://doi.org/10.1007/s12182-019-00404-1.

58. Zhou, Y.; Wu, X.; Zhong, X.; Sun, W.; Pu, H.; Xiaojun, J. Zhao Surfactant-Augmented Functional Silica Nanoparticle Based Nanofluid for Enhanced Oil Recovery at High Temperature and Salinity. ACS Appl. Mater. Interfaces 2019, 11 (49), 45763-45775. DOI: 10.1021/acsami.9b16960.

59. Sharma, T.; Kumar, G.S.; Chon, B.H.; Sangwai, J.S. Viscosity of the oil-in-water Pickering emulsion stabilized by surfactant-polymer and nanoparticle-surfactant-polymer system. Korea-Aust. Rheol. J. 2014, 26, 377-387. https://doi.org/10.1007/s13367-014-0043-z.

60. Baldygin, A.; Nobes, D.S.; Mitra, S.K. New Laboratory Core Flooding Experimental System. Ind. Eng. Chem. Res. 2014, 53 (34), 13497-13505. DOI: 10.1021/ie501866e.

61. Mahdavi, S.; James, L.A. High pressure and high-temperature study of CO2 saturated-water injection for improving oil displacement; mechanistic and application study. Fuel 2020, 262, 116442. https://doi.org/10.1016/j.fuel.2019.116442.

62. Zampieri, M.F.; Ferreira, V.H.S.; Quispe, C.C.; Sanches, K.K.M.; Moreno, R.B.Z.L. History matching of experimental polymer flooding for enhanced viscous oil recovery. J Braz. Soc. Mech. Sci. Eng. 
2020, 42, 205. https://doi.org/10.1007/s40430-020-02287-5.

63. Ghahfarokhi, A.J.; Torsaeter, O. Modeling Wettability Alteration in Low Salinity Water Flooding. Presented at 81st EAGE Conference \& Exhibition, 2019. DOI: 10.3997/2214-4609.201900720.

64. Kok, M.V. Performance Estimation of Water Flooding in Oil Recovery. Energy Sources, Part A 2009, 31, 560-567. DOI: 10.1080/15567030802463943.

65. Nandwani, S.K.; Chakraborty, M.; Gupta, S. Chemical flooding with ionic liquid and nonionic surfactant mixture in artificially prepared carbonate cores: A diffusion controlled CFD simulation. J. Pet. Sci. Eng. 2019, 173, 835-843. https://doi.org/10.1016/j.petrol.2018.10.083.

66. Kamali, F.; Hussain, F. Field-scale simulation of $\mathrm{CO}_{2}$ enhanced oil recovery and storage through SWAG injection using laboratory estimated relative permeabilities. J. Pet. Sci. Eng. 2017, 156, 396-407. https://doi.org/10.1016/j.petrol.2017.06.019.

67. Dahbag, M.S.B.; Hossain, M.E. Simulation of Ionic Liquid Flooding for Chemical Enhance Oil Recovery Using CMG STARS Software. Soc. Pet. Eng. 2016, SPE-182836-MS; 1-14. DOI: 10.2118/182836-MS.

68. Salmo, I.C.; Pettersen, O.; Skauge, A. Polymer Flooding at an Adverse Mobility Ratio: Acceleration of Oil Production by Crossflow into Water Channels. Energy Fuels 2017, 31 (6), 5948-5958. DOI: 10.1021/acs.energyfuels.7b00515.

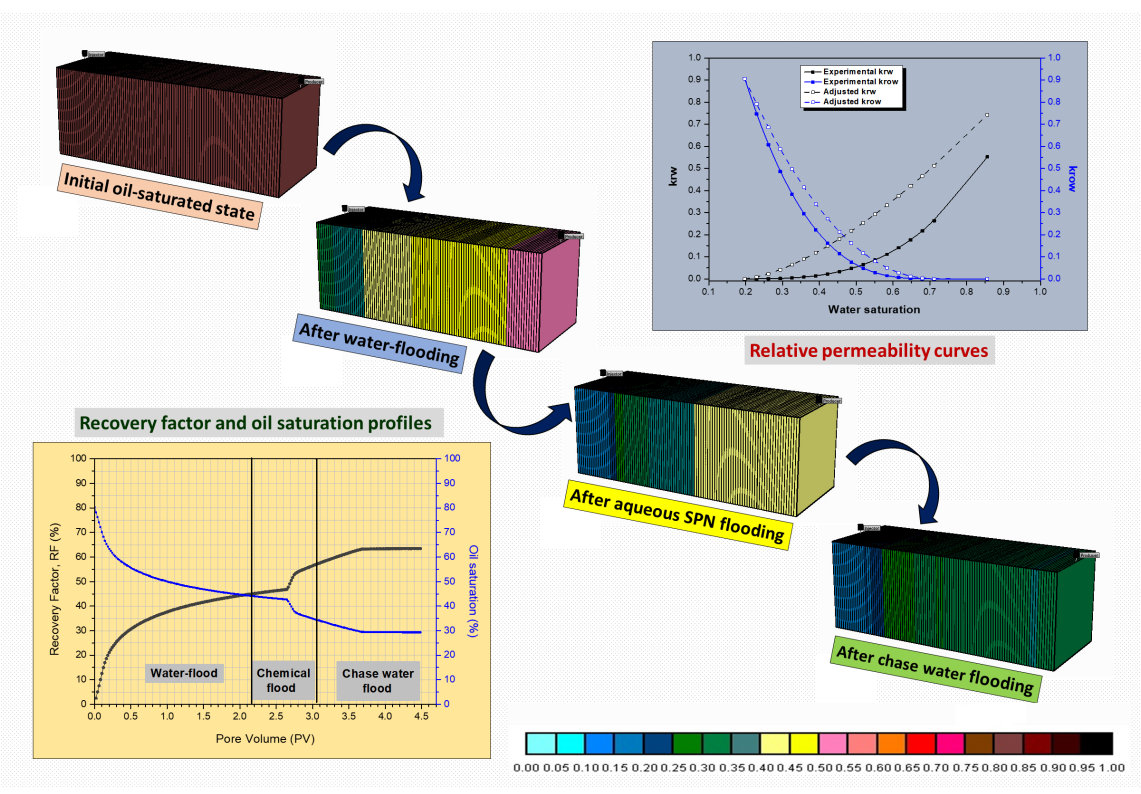

